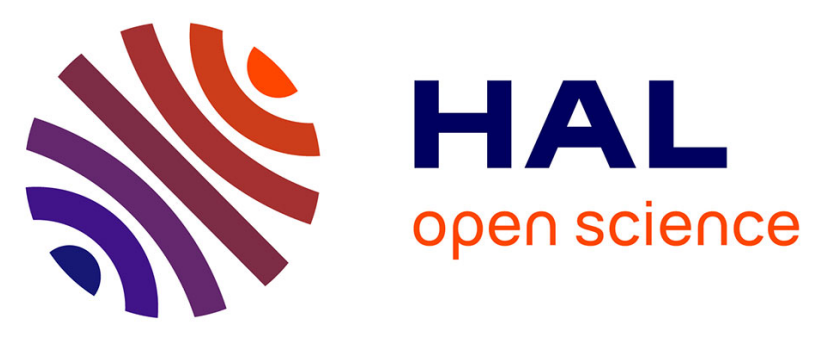

\title{
Influence of submonthly air-sea coupling on heavy precipitation events in the Western Mediterranean basin
}

Ségolène Berthou, Sylvain Mailler, Philippe Drobinski, Thomas Arsouze, Sophie Bastin, Karine Béranger, Emmanouil Flaounas, Cindy Lebeaupin Brossier, Samuel Somot, Marc Stéfanon

\section{To cite this version:}

Ségolène Berthou, Sylvain Mailler, Philippe Drobinski, Thomas Arsouze, Sophie Bastin, et al.. Influence of submonthly air-sea coupling on heavy precipitation events in the Western Mediterranean basin. Quarterly Journal of the Royal Meteorological Society, 2016, 142 (S1), pp.453-471. 10.1002/qj.2717 . insu-01242008

\section{HAL Id: insu-01242008 \\ https://hal-insu.archives-ouvertes.fr/insu-01242008}

Submitted on 19 Jul 2016

HAL is a multi-disciplinary open access archive for the deposit and dissemination of scientific research documents, whether they are published or not. The documents may come from teaching and research institutions in France or abroad, or from public or private research centers.
L'archive ouverte pluridisciplinaire HAL, est destinée au dépôt et à la diffusion de documents scientifiques de niveau recherche, publiés ou non, émanant des établissements d'enseignement et de recherche français ou étrangers, des laboratoires publics ou privés. 


\title{
Influence of submonthly air-sea coupling on heavy precipitation events in the Western Mediterranean basin.
}

\author{
Ségolène Berthou ${ }^{\mathrm{a} *}$, Sylvain Mailler ${ }^{\mathrm{a}}$, Philippe Drobinski ${ }^{\mathrm{a}}$, Thomas Arsouze ${ }^{\mathrm{a}, \mathrm{b}}$, Sophie \\ Bastin $^{c}$, Karine Bérangerd, Emmanouil Flaounas ${ }^{\mathrm{f}}$, Cindy Lebeaupin Brossier ${ }^{\mathrm{e}}$, Samuel \\ Somot $^{\mathrm{e}}$, Marc Stéfanon ${ }^{\mathrm{g}}$ \\ ${ }^{a}$ IPSL/Laboratoire de Météorologie Dynamique, Université Paris Saclay/École Polytechnique, Paris \\ Sciences-Lettres/ENS, Sorbonne Universités/UPMC, ENPC, CNRS, Palaiseau, France, \\ b ENSTA-ParisTech, Unité de Mécanique, Palaiseau, France, \\ c IPSL/Laboratoire ATmosphère, Milieux, Observations Spatiales, Guyancourt, France, \\ d LTHE, Grenoble, and IPSL/LMD, Palaiseau, France, \\ e GAME-CNRM, Météo France/CNRS, Toulouse, France, \\ e National Observatory of Athens, Athens, Greece, \\ ' IPSL/Laboratoire des Sciences du Climat et de l'Environnement, CEA/CNRS/UVSQ, Gif sur Yvette, \\ France \\ ${ }^{*}$ Correspondence to: segolene.berthou@lmd.polytechnique.fr
}

Heavy precipitation events (HPEs) can be a major cause of damage and casualties in the Mediterranean basin. With the use of atmosphere-ocean coupled regional climate models (AORCMs) and the advantage of 24 years of simulation (1989-2012), we identified regions with potential impact of submonthly air-sea coupling on HPEs among the regions hit by heavy rain during HyMeX 1st special observation period (SOP1): Valencia in Spain, the Cévennes in Southern France, Liguria in Northwestern Italy, Calabria in Southern Italy and Northeastern Italy. A first evaluation of the two AORCMs (MORCE and CNRM-RCSM4) against gridded precipitation datasets showed that 70 to $90 \%$ of the 30 most intense HPEs simulated were observed HPEs for most regions. The Cévennes, Valencia and Calabria were the only three regions to show a statistical relationship between rain differences and SST differences where the low-level jets that feed the events most frequently blow. This sensitivity of precipitation to SST changes is due to low-level wind changes related with changes in surface heat fluxes. Based on the calculation of submonthly variations in these regions during HyMeX, HPEs on the 28/09/2012 and 12/10/2012 in Valencia and on 25-26/10/2012 in the $\mathrm{C}^{\prime}$ evennes have most probably been affected by submonthly air-sea coupling.

Key Words: Heavy precipitation events, Mediterranean, air-sea coupling, atmosphereocean regional climate model

Received ...

Citation: ... 


\section{Introduction}

The configuration of the Western Mediterranean basin is an arc of mountains, from southwest to northeast: the Atlas mountains, the Iberian and Betic chains in Spain, the Pyrenees, the Massif Central in France, the Alps, the Appenines in Italy and the Dinaric Alps in the Balkan peninsula (Fig. 1a) surrounding the Western Mediterranean basin. The coastal Atlas mountains, the Iberian and Betic chains, the Massif Central and the Appenines are mid mountain ranges with summits around $2000 \mathrm{~m}$ whereas the Alps and the Pyrenees reach around $3000 \mathrm{~m}$ on the Mediterranean side. When synoptic and lower-level conditions are favourable, this setting makes the whole region often subject to heavy precipitation events (HPEs) happening at local scales. Such events are characterized by large amounts of precipitation over a short period of time (typically more than $100 \mathrm{~mm}$ in $24 \mathrm{~h}$ recorded by raingauges), sometimes leading to flash-floods with damage and casualties. HPEs provide approximately $60 \%$ of the total seasonal precipitation (October to March) in the northern Mediterranean coastal area (Toreti et al. 2010).

They are linked with the large temperature contrast between the sea and the continent that favour instability in this season together with the transition from a subtropical regime in summer to the midlatitude weather perturbation systems in winter. This also favours Mediterranean cyclones that were assessed to be linked with about $90 \%$ of the precipitation events with amounts larger than $60 \mathrm{~mm}$ per day in the Western Mediterranean basin by Jansà et al. (2001). Cyclones, interactions with topography and self organisation of convection are typical mechanisms that can localize precipitation systems fed by low-level moist jets and induce very high precipitation amounts (García-Herrera et al. 2005; Houze 2004; Ducrocq et al. 2008; Pastor et al. 2010; Bresson et al. 2012; Ricard et al. 2012). This also most often involves a slow evolving large-scale trough that can become a cutoff low. Depending on the location of the trough, precipitation occurs in eastern Spain (Romero et al. 1999; Martínez et al. 2008; Riesco Martn et al. 2014), in Southern France (Nuissier et al. 2008; Toreti et al. 2010; Nuissier et al. 2011), in the Alps (Martius et al. 2008; Hoinka et al. 2006) or in Italy (Rudari et al. 2005).

Another characteristic of the Mediterranean area is the interaction between the orography and the large-scale flow that can generate strong winds (over $20 \mathrm{~m} \mathrm{~s}^{-1}$ ) in the lower levels of the atmosphere (Chronis et al. 2011) through channeling and/or mountain wave overturning and eventual breaking. Local names have been given to these phenomena (Fig. 1c): in Spain the Cierzo (westerly wind in the Ebro valley), in France the Tramontane (westerly wind in the Aude valley, Drobinski et al. (2001)), the Mistral (northerly wind in the Rhône valley, Guénard et al. (2005, 2006); Drobinski et al. (2005)), in the Balkans the Bora (north-easterly wind across the Dinaric Alps, Grisogono and Belušić (2009)) or the Vandevales in the Alboran sea. Other intense easterly or southeasterly winds occur during intense cyclonic circulation with less strong orographic interaction (Sirocco, Libeccio, Chili) blowing from Africa on Fig. 1c. All these intense winds blow intermittently (Chronis et al. 2011; Herrmann et al. 2011) and generate intense air-sea fluxes (Flamant 2003; Lebeaupin Brossier and Drobinski 2009). They are mainly responsible for the large submonthly variability in the sea surface temperature (SST) of the Mediterranean together with the ocean circulation, the cloud cover and other mechanisms.

The wind strength necessary to create submonthly SST changes depends on the mixed layer depth, which varies between seasons and regions (Houpert et al. 2015) and on stratification. It also depends on the airsea temperature and moisture contrasts and on the wind persistence (Lebeaupin Brossier and Drobinski 2009; Small et al. 2012). Anomalies after strong wind events can be persistent because of the heat capacity of the mixed layer which depends on its depth and the time needed for restratification (1 to 3 weeks). In the Gulf of Lions where a cyclonic gyre is present and enhanced by Mistral (Béranger et al. 2010), this last process can be important. As an example of cooling and persistence, Lebeaupin Brossier et al. (2013) study a case of Mistral in autumn in the Gulf of Lions with a coupled simulation when the simulated mixed layer was $50 \mathrm{~m}$ deep. $10 \mathrm{~m} \mathrm{~s}^{-1}$ winds blew for 2 days with peaks at $25 \mathrm{~m} \mathrm{~s}^{-1}$. This lead to total heat fluxes of $400 \mathrm{~W} \mathrm{~m}^{-2}$ on average over the northwestern Mediterranean lasting a whole day (Lebeaupin Brossier and Drobinski 2009). They caused the rapid breaking of the ocean surface stratification and then the mixing of the present subsurface cold waters isolated inside the gyre from the warmer surface waters. This cooling due to the entrainment at the mixed layer bottom was quantified to a cooling of 0.6C.day which was 3 times larger than the cooling due to horizontal advection and 2 times larger than the one due to surface heat fluxes. This anomaly persisted for a week after the Mistral stopped.

This article addresses the question of whether or not these SST submonthly variations can influence HPEs in various regions.

Several studies investigated the sensitivity of HPEs to changes in the SST thanks to numerical mesoscale simulations. In the region of Valencia in Spain, Pastor et al. (2001) used different SST fields to force simulations of two cases. They show that an increase of SST upstream of the Valencia region (by 2 to $5^{\circ} \mathrm{C}$ ) could lead to an increase (by a factor of 2) and a displacement of the precipitation maximum of a HPE. Pastor et al. (2015) further showed that for three HPEs in this same region, the SST area with the greatest influence on model precipitation results was the one situated between the Valencia coast and the Balearic Islands. It was shown that if intense heat/moisture air-sea exchanges were shut off by decreasing the SST to $10^{\circ} \mathrm{C}$ in this region, precipitation in Valencia were suppressed in 2 out of 3 cases. For these 3 cases, remote regions revealed a more moderate impact: switching off the fluxes had only an effect of modulation of the HPEs.

Millán et al. (1995) give another type of impact of the SST on precipitation. They infer that changes in SST have an impact on the convergence zone through the influence on the convective drag that occurs when colder continental air is advected over warmer SST (theory of the Back Door Front, (Millán et al. 1995)). 

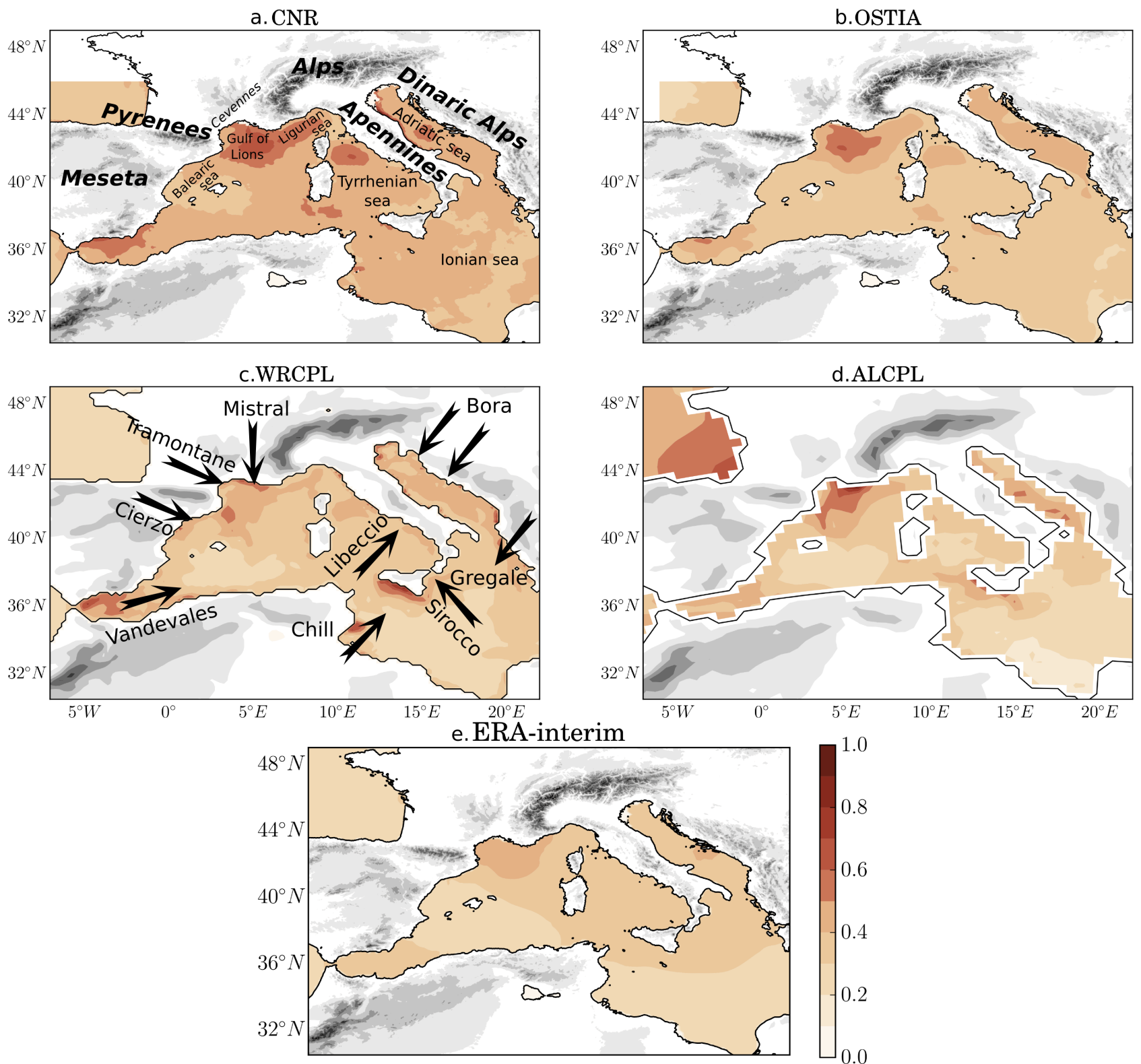

Figure 1. RMS of the submonthly variability of the SST (calculated as the deviation from the monthly moving average) for September to December, for the period 1989 to 2012 and for various datasets (CNR, OSTIA, ERA-Interim: see section 2.3) or simulations (WRCPL, ALCPL: see section 2.1.3).

Lebeaupin et al. (2006) showed with the help of high resolution numerical weather forecast simulations that a change in the mean spatial $\mathrm{SST}$ of $3^{\circ} \mathrm{C}$ had a strong influence on the intensity of rain events through changes in surface heat fluxes in three case studies over the Cévennes area. They also showed that the average upstream changes had more effect than changes in the very fine spatial structure of the SST. The mechanisms involved in the precipitation changes depend on the type of precipitation: for mesoscale convective systems (MCSs), the SST impacts on the intensity and location of convection whereas for quasi-stationary frontal systems, the response to the SST includes interaction between deep convection and frontal dynamics. Lebeaupin Brossier et al. (2013) used two regional climate twin simulations, one coupled to an ocean model and the other forced by lowresolution analyses. The SST differences between them were arising from both air-sea coupling and from long-term biases of the oceanic model. These SST differences produced important modifications of precipitation during a HPE over the Cévennes. Using 20-year regional climate simulations, Berthou et al. (2014) were able to separate this long-term bias of the oceanic model from the submonthly air-sea coupling. They showed that statistically, at least for the HPEs represented by the model, a significant correlation exists between submonthly SST variations and modulation of the precipitation amount and location. Precipitation was more strongly impacted when the SST changes due to coupling effects were large. To explain dipole-like differences in the precipitation field, Berthou et al. (2015) showed the impact of SST changes on the low-level dynamics in regional climate simulations through i) impact on the blocking effect of the flow by the orography through changes in the low-level atmospheric stability; ii) impact on surface pressure through the convergence 
of temperature anomalies; iii) direct impact on convergence zone dynamics by changes in the low-level atmospheric stability.

Katsafados et al. (2011) studied the effects of different SST forcings on a deep low-pressure system over the Eastern Mediterranean. Their results indicate that surface fluxes have a limited impact on the intensity and the location of this storm, mainly controlled by the upper atmospheric conditions. However, they note the existence of spatio-temporal deviations on the distribution of precipitation. The displacement of the rainbands appearing in the various experiments can possibly be associated with the simulated surface heat fluxes that induce stronger vertical momentum mixing responsible for mesoscale features in the surface wind convergence field.

Overall, these studies show that typical changes by a few degrees in the SST can modulate HPEs rather than act as a causal factor in their occurrence over the Mediterranean. This can be explained by the fact that the contribution of the Mediterranean to moisture feeding occurs over a few days before events occurring in Southern France (Duffourg and Ducrocq 2011). Therefore, a change of a few degrees in the SST may not significantly change the moisture and stability of the atmosphere: the preconditions mostly stay similar.

Regional climate models ( $\mathrm{RCMs}$ ) have proved to have some ability in representing mesoscale patterns of observed precipitation extremes that are constrained by the orography (Frei et al. 2006; Herrera et al. 2010; Colin 2012). In fact, Sánchez et al. (2004); Kyselý et al. (2012); Rajczak et al. (2013) among others investigated the representation of extreme rain events and their projection into the future with RCMs. Moreover, coupled atmosphere-ocean RCMs (AORCMs) show good ability to reproduce strong wind episodes (Herrmann et al. 2011) and submonthly variations of SST (The PROTHEUS Group et al. 2009; Sevault et al. 2014). In this study, two AORCMs are used with different sets of simulations running over 24 years.

The Hydrological cycle in Mediterranean experiment (HyMeX) which aims at better understanding the water cycle in the Mediterranean (Drobinski et al. 2014) had a special focus on heavy precipitation events in autumn 2012 (from September 5 to November 4) with a measurement campaign (1st special observation period SOP1) described in Ducrocq et al. (2014). Six coastal regions of the Western Mediterranean basin were hit by at least one event of more than $100 \mathrm{~mm}$ as shown by the maximum precipitation recorded by the rain gauges (Fig. 2). This study will focus on these six regions:

- The region south of Valencia in Spain (Val)

- The foothills of the Massif Central in France called the Cévennes (Cvn)

- Liguria in Italy between Genoa and Florence (Li)

- Central Italy from Rome to Naples (CeIt)

- Calabria (Cal)

- Northeastern Italy around Trieste and Udine (NEI)

In the line of Berthou et al. (2014) who use regional climate simulations and study statistically the link between changes in SST and changes in HPE in the Cévennes area, this study inquires if other regions show HPEs that are sensitive to SST changes, in particular SST submonthly variations. Moreover, this study also aims to give an index based on observed SST that could provide information on how strongly a HPE has been affected by submonthly variations of SST mainly due to local strong wind regimes blowing within a month of the event. In section 2, models, simulations and gridded products based on observations are described. In section 3 we examine the ability of the two regional climate models to represent the intensity and the chronology of HPEs as well as submonthly SST variations. This allows us to statistically assess the response of HPEs to variations in SST in section 4 and to compare the index based on the variations of the modeled SST to the ones based on the observed SST in section 5. Finally, we identify HyMeX HPEs that were potentially influenced by submonthly air-sea coupling thanks to this index and the relationship build in section 4 .

\section{Materials and methods}

\subsection{Models}

\subsubsection{MORCE platform}

The MORCE (model of the regional coupled Earth system) platform is the first two-way air-sea coupled system (AORCM) used in this study (Drobinski et al. 2012). The MORCE system is used in HyMeX (Drobinski et al. 2014) and the Coordinated downscaling experiment (CORDEX) of the World climate research program (WCRP) (Giorgi et al. 2009) in the Mediterranean area (Med-CORDEX, Ruti et al. (2015)).

The atmospheric model within the MORCE system is the non-hydrostatic weather research and forecasting model (WRF) version 3.1.1 of the National Center for Atmospheric Research (NCAR) (Skamarock et al. 2008). The domain covers the Mediterranean basin in line with CORDEX requirements with a horizontal resolution of $20 \mathrm{~km}$. It has 28 vertical levels from the surface to $50 \mathrm{hPa}$ using sigma coordinates. The first $1000 \mathrm{~m}$ are resolved on 8 levels.

The boundary layer parametrization is a $\mathrm{K}$-profile scheme improved by Noh et al. (2003) (YSU). The surface-layer is the Monin-Obukov scheme (Stull 1994). The cumulus convection scheme is the Kain-Fritsch scheme (Kain 2004). It is a mass flux parametrisation scheme with a closure assumption based on CAPE. Convection is triggered when the temperature of a $60 \mathrm{hPa}$ layer is higher than the environment temperature at its condensation level. A temperature deviation is added to the parcel depending on the larger scale vertical velocity in order to trigger convection in a sub-cloud converging environment.

Two land surface models (LSM) have been used in this study, namely the Rapid Update Cycle (RUC) LSM and the thermal diffusion (DIFF) LSM. The RUC LSM (Smirnova et al. 1997) resolves heat and moisture transfer in 6 layers from 0 to $3 \mathrm{~m}$. This scheme accounts for the different phases of soil surface water, vegetation effects (evaporation from leaf stomata, solar radiation 

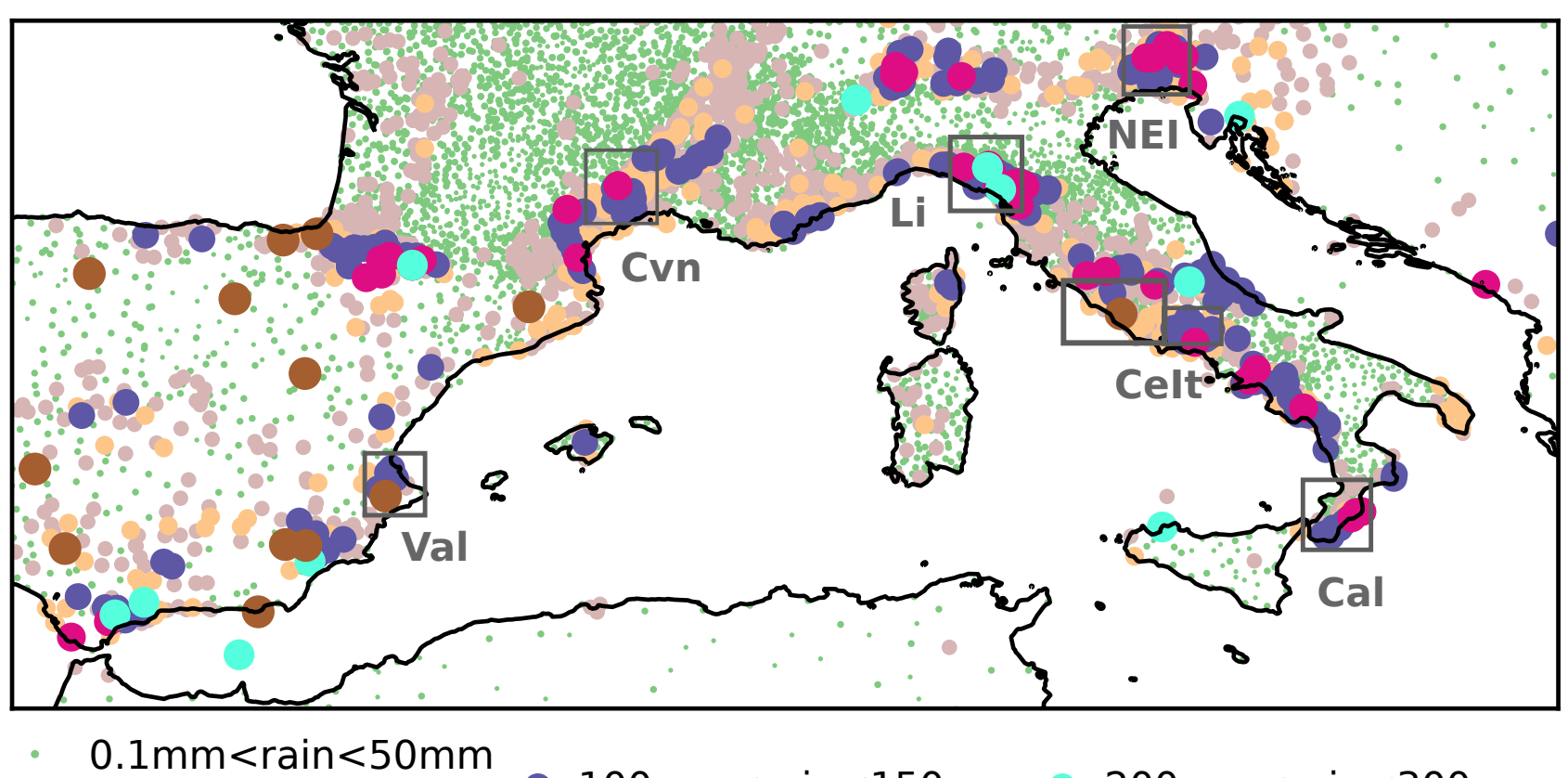

\section{- $50 \mathrm{~mm}<$ rain $<75 \mathrm{~mm}$ - $75 \mathrm{~mm}<$ rain $<100 \mathrm{~mm}$}

\section{$100 \mathrm{~mm}<$ rain $<150 \mathrm{~mm} \bigcirc 200 \mathrm{~mm}<$ rain $<300 \mathrm{~mm}$ $150 \mathrm{~mm}<$ rain $<200 \mathrm{~mm}$ rain $>300 \mathrm{~mm}$}

Figure 2. Rain maximum for every raingauge during HyMeX SOP1. Grey boxes indicate the regions selected for the study. Figure similar to Fig. 6 in Ducrocq et al. (2014).

absorption, heat fluxes etc.) and canopy water. The DIFF LSM is based on a 5-layer simple scheme where the energy budget includes radiation, sensible and latent heat. The last layer is only at $16 \mathrm{~cm}$ depth, under which the temperature is fixed at a deep-layer average. Vegetation effects are not taken into account. During the simulation, an empirical coefficient, called soil moisture availability is applied for latent heat flux calculation. It has been set to its wintertime values, therefore not permitting the simulation of soil moisture deficit situations. The complete set of physical parametrizations can be found in Lebeaupin Brossier et al. (2015) and Stéfanon et al. (2014).

The ocean model of MORCE is Nucleus for European Modelling of the Ocean (NEMO) (Madec and the NEMO Team 2008). It is used in a regional eddy-resolving Mediterranean configuration MED12 (Lebeaupin Brossier et al. 2011; Beuvier et al. 2012) with a $1 / 12^{\circ}$ horizontal resolution, which represents about $6.5-7 \mathrm{~km}$ in the Gulf of Lions. In the vertical, MED12 has 50 stretched z-levels with a resolution of $1 \mathrm{~m}$ for the surface layer. The initial conditions for 3D potential temperature and salinity fields are provided by the Mediterranean oceanic database version 4 (MODB4) climatology (Brankart and Brasseur 1998) except in the Atlantic zone between $11^{\circ} \mathrm{W}$ and $5.5^{\circ} \mathrm{W}$, where the Levitus et al. (2005) climatology is applied. In this area, a three dimensional relaxation toward this monthly climatology is used. River runoff and the Black Sea water input come from a climatology (Beuvier et al. 2012) and their freshwater flux is set at the mouths of the 33 main rivers and at the Dardanelles Strait respectively. Smaller river runoffs are summed and set as a homogeneous coastal runoff around the Mediterranean Sea as in Beuvier et al. (2012). Further details on the ocean model parametrization can be found in Beuvier et al. (2012) and Lebeaupin Brossier et al. (2013).

\subsubsection{The CNRM regional climate system model: CNRM-RCSM4}

The coupled regional climate system model developed at CNRM (Nabat et al. 2015; Sevault et al. 2014) includes the regional climate atmospheric model ALADIN Climate version 5 (Colin et al. 2010; Herrmann et al. 2011), the land surface model ISBA (Noilhan and Mahfouf 1996), the river routing scheme TRIP (Decharme et al. 2010) and the regional ocean model NEMO-MED8 (Beuvier et al. 2010).

The ALADIN-Climate model is a bi-spectral regional climate model with a semi-implicit semi-Lagrangian advection scheme. A 2-D bi-Fourier decomposition is used (Haugen and Machenhauer 1993). The convection scheme is a mass-flux scheme with convergence of humidity closure based on Bougeault (1985). The triggering function for convection is based on CAPE and moisture convergence. The cloud scheme is based on the Ricard and Royer (1993) statistical scheme and on the large-scale precipitation described by Smith (1990). The radiative scheme is derived from Morcrette (1989) and from the IFS model of the ECMWF. The planetary boundary layer turbulence physics including the computation of the turbulent air/sea fluxes is based on Louis (1979), and the interpolation of the wind speed from the first layer of the model (about $30 \mathrm{~m}$ ) to the $10 \mathrm{~m}$ height follows Geleyn (1988). The domain has a Lambert conformal projection at a horizontal resolution of $50 \mathrm{~km}$ centered at $14.8 \mathrm{E}, 43.8 \mathrm{~N}$ with 128 longitude grid-points and 90 latitude gridpoints including the biperiodisation (11 grid-points) and the relaxation zones $(2 \times 8$ grid-points $)$. The ISBA 
model is the land-surface scheme interfaced with the atmospheric model. This version of the model has 31 vertical levels. The time step used is $1800 \mathrm{~s}$.

The ocean model NEMO-MED8 (Beuvier et al. $2010)$ is a regional version of the NEMO-V2.3 ocean model (Madec and the NEMO Team 2008). NEMO-MED8 covers the Mediterranean Sea (without the Black Sea) plus a buffer zone including the adjacent part of the near Atlantic Ocean, where a three-dimensional damping is performed towards temperature and salinity (monthly data, NEMOVARCOMBINE , Balmaseda et al. (2010)), so that the circulation through the strait is simulated with realistic Atlantic waters. A sea level relaxation is also applied on this Atlantic part of the domain towards the same reanalysis. This version has a horizontal resolution between 9 and $12 \mathrm{~km}$, and 43 vertical levels, with layer thickness increasing from $6 \mathrm{~m}$ to $200 \mathrm{~m}$. The partial steps definition of the bottom layer is used, and the surface is parameterized with the free surface configuration, filtered formulation.

The TRIP river routing model is used to convert the simulated runoff by the ISBA land surface scheme into river discharge using a river channel network at $0.5^{\circ}$ resolution (Decharme et al. 2010). Coupling between all the different components is achieved by the OASIS3 coupler (Valcke 2013) at a one day frequency.

\subsubsection{Configuration of MORCE and CNRM-RCSM4 and simulations}

For each model, one atmosphere-ocean fully coupled simulation and one atmosphere-only simulation forced by ERA-Interim SST are run. We call them respectively CPL and CTL simulations in the rest of the study. In the atmosphere only simulations, SST from ERAInterim is updated every day in WRF and every month in ALADIN (Table 1). Thus, the daily difference between the SST of NEMO in the coupled simulations and ERA-Interim in the atmosphere-only simulations can be much larger for CNRM-RCSM4 than for MORCE (see Fig. 3). A third simulation called SMO (for monthly-smoothed SST) was run with MORCE. SMO is an atmosphere-only simulation with the same characteristics as the CTL simulation, except that instead of the ERA-Interim SST, a new SST field has been used for the forcing of the atmospheric model. This forcing has been designed in order to retain the same climatology and diurnal cycle as the CPL SST, but without the submonthly SST variations. For that purpose, the SST value used to force the RCM at each target time step was calculated by performing a central moving average with a 31-day window, retaining only the 31 time steps in the time window that correspond to the same GMT time as the target time step. This way, the diurnal cycle (as well as its seasonal variations) is preserved, as are all the persistent spatial structures that exist in CPL. The high-frequency airsea coupling effects (submonthly variations), however, are not present in SMO (Fig. 3).

CNRM-RCSM4 simulations run from 1979 to 2012 but the period used in this study is 1989-2012. We will call them ALCPL for the coupled version and ALCTL for the version forced with the ERA-Interim SST. MORCE is used with two soil schemes: RUC and
DIFF. Each version of the model is run 3 times in CPL, CTL and SMO configurations. WRCPL, WRCTL and WRSMO are the versions with the RUC surface scheme from 1989 to 2012 and WDCPL, WDCTL and WDSMO are the versions with the DIFF surface scheme from 1989 to 2008. Table 1 sums up all the simulations used.

For both atmospheric models, initial and lateral conditions are taken from the European Centre for Medium-Range Weather Forecasts (ECMWF) ERAInterim reanalysis (Simmons et al. 2007) provided every $6 \mathrm{~h}$ with a $0.75^{\circ}$ resolution.

Nudging above the boundary layer is used by both models in order to avoid a large-scale that would diverge from the observed large-scale structures inside the limited area (Stauffer and Seaman 1990; Salameh et al. 2010; Omrani et al. 2013). The main disadvantage of this technique is to dampen the response of the free troposphere to surface changes. However, the major advantage is that the large-scale still respects the ERA interim one and the chronology of events is similar between two simulations that have different surface boundary conditions (Herrmann et al. 2011). In MORCE, indiscriminate nudging (Newtonian-type nudging) is used to constrain the fields above the planetary boundary layer with a coefficient of $5.10^{-5} s^{-1}$ (about $5.5 \mathrm{~h}$ ) for temperature, humidity and velocity components. The nudging coefficient was chosen following Omrani et al. (2013) so that the relaxation time is large enough to constrain the large scale without prohibiting smallscale evolution. CNRM-RCSM4 uses a spectral nudging technique (Herrmann et al. 2011; Sevault et al. 2014). Temperature, specific humidity, wind vorticity, wind divergence and the logarithm of the surface pressure are nudged with a respective maximum e-folding time of $24 \mathrm{~h}, 24 \mathrm{~h}, 6 \mathrm{~h}, 48 \mathrm{~h}$ and $24 \mathrm{~h}$. The maximum e-folding time is reached above $700 \mathrm{hPa}$ and for larger scales of $1280 \mathrm{~km}$. The nudging linearly decreases between 700 and $850 \mathrm{hPa}$ in altitude and 1280 and $640 \mathrm{~km}$ in horizontal scales. Therefore, the scales smaller than ERA-Interim scales are not nudged.

In the MORCE model, the ocean starts from 3D potential temperature and salinity fields provided by the MODB4 climatology (Brankart and Brasseur 1998) in 1989 while a 21 year spin-up is performed in CNRMRCSM4 using the 1980-1986 period in a three-time loop period (Sevault et al. 2014) before starting in 1979. This means that the ocean starts at rest and is forced by the atmospheric fields of 1980-1986 three times in a row.

The two versions of WRF show strong differences in the $2 \mathrm{~m}$ temperature, especially in summer where the simulations using DIFF LSM show weaker temperatures by $5-6^{\circ} \mathrm{C}$ over continental surfaces compared to the ones using RUC LSM (Flaounas et al. 2013): this potentially has an impact on the atmospheric stability. The two WRF configurations result in very different land surface conditions and add a member in the analysis of the response of precipitation to SST changes.

The comparison between CPL and CTL at the daily scale will mainly indicate the impact of a different SST on the atmospheric field. This different SST comes 


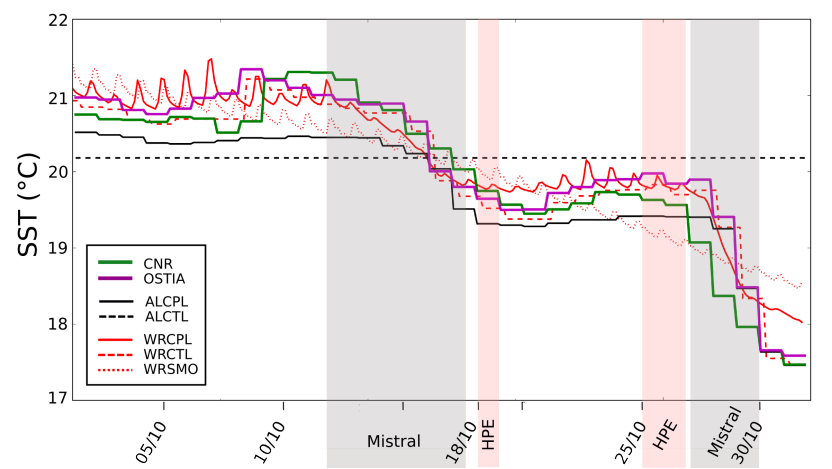

Figure 3. Averaged SST over the upstream region of the Cévennes (red box in Fig. 4) for the month of October during HyMeX SOP1 for different datasets. Periods of northerly or northwesterly wind (Mistral) above $10 \mathrm{~m} \mathrm{~s}^{-1}$ in WDCPL are highlighted in grey, periods of HPE occuring in the blue box in Fig. 4 are highlighted in red.

from both coupling effects and long-term biases in the model (Sevault et al. 2014; Lebeaupin Brossier et al. 2015), in addition to the monthly SST update in ALADIN. WDCPL and WRCPL show quite different biases and are therefore interesting to compare in the rest of the study. The comparison of CPL with SMO for MORCE will permit a more physical interpretation since differences arise only from coupling at the submonthly scale (e.g. strong wind bursts cooling the SST).

\subsection{Gridded rain datasets}

In order to evaluate the models in terms of extreme precipitation events in the 6 regions selected for this study (in section 3.1), different regional gridded datasets based on rain gauges were used and are presented hereafter. Table 2 shows which dataset was used for each region;

\subsubsection{SAFRAN (France)}

Système d'analyse fournissant des renseignements atmosphériques à la neige (SAFRAN) is a precipitation analysis for continental France that uses an optimal interpolation method. One of the main features of SAFRAN is that the analyses are performed over climatically homogeneous zones, which are areas of irregular shape covering a surface usually smaller than $1000 \mathrm{~km}^{2}$ and where the horizontal climatic gradients (especially for precipitation) are weak. SAFRAN estimates one value of each parameter for each zone at several altitude levels. Within the zone, analyzed parameters depend only on elevation and aspect. First, SAFRAN performs a quality control of the observations. This is an iterative procedure based on the comparison between observed and analyzed quantities at the observation location. There were 3675 measurement stations for 2004/05. The precipitation analysis is performed daily at $0600 \mathrm{UTC}$, to include in the analysis the numerous rain gauges that measure precipitation on a daily basis (in particular in the climatological and snow networks). The first guess is a very simple and constant field. An hourly separation is then performed but in this study we use the daily precipitation amount. Further description can be found in Quintana-Seguí et al. (2008).

\subsubsection{Alps dataset}

The Alpine rain gauge dataset typically comprises 5500 observations on any day of the period 1971-2008. The analysis is based on a first guess for a day that is the long-term mean precipitation (period 1971-1990) of the relevant calendar month. The precipitation-elevation relationship is calculated locally and taken into account in this first guess. Then, an anomaly is computed for every grid point using the stations located within a radius that depends on the station density. It can be up to $60 \mathrm{~km}$ from the grid point. The dataset has a $5 \mathrm{~km}$ resolution but its effective resolution is closer to $10-15 \mathrm{~km}$. The dataset is provided by the Federal Office of Meteorology and Climatology MeteoSwiss. Further description can be found in Isotta et al. (2014).

\subsubsection{Spain02}

Spain02 is a high-resolution $\left(0.2^{\circ}\right)$ daily precipitation gridded dataset developed for peninsular Spain and the Balearic islands using 2756 quality-controlled stations over the time period from 1971 to 2010 (Herrera et al. 2012). The grid was produced applying the kriging method in a two-step process. First, the occurrence was interpolated using a binary kriging and, in a second step, the amounts were interpolated by applying ordinary kriging to the occurrence outcomes. The elevation is not explicitly included in the development of the dataset because the available dense gauge network appropriately represents the orography corresponding to the $0.2^{\circ}$ grid. Explicit comparison with E-OBS dataset shows the better performance in terms of amount and spatial distribution of Spain02 to capture extreme events, especially in the region of Valencia (Herrera et al. 2012).

\subsection{4. $E-O B S$}

The European Climate Assessment and Data set (ECA\&D) project called (E-OBS) integrates data for 62 countries at 4823 meteorological stations throughout Europe and the Mediterranean area. The gridded dataset is produced with a horizontal resolution of $0.25^{\circ}$ by $0.25^{\circ}$. Haylock et al. (2008) describe the method used to compute the gridded product: it is a three-step process of interpolation. First the monthly precipitation totals are interpolated using threedimensional thin-plate splines, then the daily anomalies are interpolated using indicator and universal kriging and finally the monthly and daily estimates are combined.

This dataset covers the whole of Europe but uses a coarser spatial density of stations than the gridded products presented before. It is therefore used for the two regions in Italy which are not covered by the other datasets: Calabria and Central Italy. Only 2 stations are located in Calabria at the eastern edge of the region and 5 stations are used for Central Italy. 


\begin{tabular}{|c|c|c|c|c|c|c|}
\hline $\begin{array}{l}\text { Shortname } \\
\text { of the set }\end{array}$ & $\begin{array}{c}\text { Shortname of the } \\
\text { simulation }\end{array}$ & Atmosphere & SST & SST update & surface & time span \\
\hline \multirow[t]{2}{*}{ ALADIN } & ALCTL & ALADIN (50km) & ERA-Interim $(80 \mathrm{~km})$ & monthly & ISBA & 1989-2012 \\
\hline & ALCPL & ALADIN (50km) & NEMO-MED8 (9-12km) & daily & ISBA & 1989-2012 \\
\hline \multirow[t]{3}{*}{ WD } & WDCTL & WRF $(20 \mathrm{~km})$ & ERA-Interim (80km) & daily & DIFF & 1989-2008 \\
\hline & WDCPL & WRF $(20 \mathrm{~km})$ & NEMO-MED12 (6-9km) & 3 hourly & DIFF & 1989-2008 \\
\hline & WDSMO & WRF (20km) & monthly smoothed CPL SST & 6 hourly & DIFF & 1989-2008 \\
\hline \multirow[t]{3}{*}{ WR } & WRCTL & WRF $(20 \mathrm{~km})$ & ERA-Interim (80km) & daily & RUC & 1989-2012 \\
\hline & WRCPL & WRF $(20 \mathrm{~km})$ & NEMO-MED12 (6-9km) & 3 hourly & RUC & 1989-2012 \\
\hline & WRSMO & WRF $(20 \mathrm{~km})$ & monthly smoothed CPL SST & 6 hourly & RUC & 1989-2012 \\
\hline
\end{tabular}

Table 1. Summary of the different simulations used in the study and their configurations. See section 2.1.3 for further details.

\begin{tabular}{cccc}
\hline Region & Gridded dataset used & Resolution & Period of interest covered \\
\hline \hline & & & \\
Valencia & Spain02 & $25 \mathrm{~km}$ & $01 / 01-1989$ to $31 / 12 / 2010$ \\
Cévennes & SAFRAN & $8 \mathrm{~km}$ & $01 / 01 / 1989$ to $31 / 07 / 2010$ \\
Liguria & Alps dataset & $5 \mathrm{~km}$ & $01 / 01-1989$ to $31 / 12 / 2008$ \\
Central Intaly & E-OBS & $25 \mathrm{~km}$ & $01 / 01-1989$ to $31 / 12 / 2012$ \\
Calabria & E-OBS & $25 \mathrm{~km}$ & $01 / 01-1989$ to $31 / 12 / 2012$ \\
Northeastern Italy & Alps dataset & $5 \mathrm{~km}$ & $01 / 01-1989$ to $31 / 12 / 2008$ \\
\hline \multicolumn{2}{c}{ Table 2. Summary of the different gridded rain datasets used in the study. }
\end{tabular}

Table 2. Summary of the different gridded rain datasets used in the study.

\subsection{SST datasets}

These SST products are built with satellite and insitu observations and are used for comparison with the SST produced by the coupled models, with a focus on submonthly variations of SST (section 3.2 and section 5).

\subsubsection{CNR SST}

The first dataset covering the whole period 19892012 in SST of the Western Mediterranean basin is the one computed by the CNR-ISAC-GOS (Consiglio Nazionale delle Ricerche, Istituto di Scienze dellAtmosfera e del Clima - Gruppo di Oceanografia da Satellite, Italy) (CNR-ISAC-GOS REP L4, described in Buongiorno Nardelli et al. (2014)). We will name it CNR SST. The data corresponds to daily (nighttime) gridded optimally interpolated satellite estimates of the foundation SST over the Mediterranean, based on AVHRR Pathfinder Version 5.2 (PFV52). The interpolation is done on the original Pathfinder grid (at $4 \mathrm{~km} \times 4 \mathrm{~km}$ spatial resolution). The SST analysis is then obtained as a linear combination of the observations, weighted directly with their correlation to the interpolation point and inversely with their cross-correlation and measurement error. The chosen scheme uses a daily decadal climatology as first guess (built from the entire PFV52 dataset), and a covariance model that assumes spatially varying parameters. The input data is selected only within a limited sub-domain (within a space-time influential radius), namely within a temporal window of ten days and a spatial influential radius ranging between 300 and $900 \mathrm{~km}$.

\subsubsection{OSTIA SST}

The Operational Sea surface Temperature and Ice Analysis (OSTIA) provides daily gap-free maps of foundation sea surface temperature at $0.05^{\circ} \times 0.05^{\circ}$ horizontal resolution, using in-situ and satellite data from infra-red radiometers. Satellite data are provided by the Pathfinder AVHRR project and reprocessed (A)ATSR data from 1985 to 2007, together with MetOp satellites, SEVIRI, GOES-East, TMI, IASI after 2007. In-situ observations come from the ICOADS data-set (drifters, ships, moored buoy). These observations may not be very numerous in the Mediterranean. Moreover, a bias correction on the observations is performed using ATSR-2/AATSR data as a key component. To provide the final SST analysis, a multi-scale optimal interpolation (OI) is performed using the previous analysis as the basis for a first guess field for the reanalyses before 2007 and using the previous analysis with a slight relaxation to climatology after. It is run daily at 06 UTC using data from a 36-h period using two error correlation scales, 10 and $100 \mathrm{~km}$, which vary depending on the region and the input data. When compared to in situ observations in the Mediterranean, mean difference is $0.11^{\circ} \mathrm{C}$ and standard deviation is $0.89^{\circ} \mathrm{C}$ which is the worst score for all the OSTIA regions covered (Donlon et al. 2011). Further information is provided by Roberts-Jones et al. (2012); Donlon et al. (2011).

\subsubsection{ERA-Interim SST}

ERA-Interim SST is not homogeneous in time: from January 1989 to June 2001, NCEP 2D-Var sea surface temperature (NCEP 2D-Var) is used. From July 2001 to December 2001, NOAA Optimum Interpolation Sea Surface Temperature v2 (NCEP OISST v2) is used. From January 2002 to January 2009 NCEP Real-Time Global sea surface temperature (NCEP RTG) is used. Finally, OSTIA is used from 2009 to 2012 (Dee et al. 2011). 


\section{Evaluation of the models}

Since this study focuses on the effects of submonthly variations of SST on heavy precipitation events, it is necessary to first give an evaluation of the representation of both phenomena in the RCMs compared to the available gridded datasets.

\subsection{Selection and representation of heavy precipitation events}

Six regions were selected for the study (Fig. 2). An evaluation of the models for all the regions is given here. A more thourough analysis is provided for the south of France in Colin (2012) for ALCTL. Time series of the spatial maximum of daily precipitation (from 0600 UTC to 0600 UTC) within each region were first computed. A threshold was then defined in the temporal series of spatial maxima to get the largest daily precipitation events that occurred in every simulation for the time period from 01/01/1989 to the end of the simulation. For the events exceeding the precipitation threshold for a number of consecutive days, only the day with the maximum precipitation was selected. 30 events were selected for ALCPL and WRCPL simulations which end on $12 / 31 / 2012$ and 25 for WDCPL which ends on $12 / 31 / 2008$ so that the number of events is 1.25 per year. The gridded datasets described in section 2.2 were regridded on each model grid by bilinear interpolation and the same selection was done. Table 3 shows the thresholds that were chosen for the simulated precipitation and the gridded precipitation datasets. One threshold was chosen for every set of simulations so that the CPL simulation contains 30 events. This number was chosen in order to get a significant number of events and to avoid too many non HPEs, as shown later in this section.

The main conclusion is that for the regions where the model is compared with gridded products based on a high density network of rain gauges, i.e. Valencia, Cévennes, Northeastern Italy and Liguria, both models underestimate heavy precipitation even when the gridded precipitation has been regridded at the model resolution, in agreement with previous studies (Déqué and Somot 2008; Colin 2012; Prein et al. 2015a). This shows that many small-scale processes enhancing precipitation during heavy rain events are missing in RCMs, probably due to a lack of resolution of topography and a lack of representation of small-scale effects (Déqué and Somot 2008; Prein et al. 2013) such as convective cold pools (Ducrocq et al. 2008). The amount of rain in Valencia is better represented with an underestimation of $30 \%$ for ALCPL and an overestimation by $15 \%$ by WRCPL. On the contrary, Northeastern Italy shows the largest differences, with the model thresholds being respectively $55 \%$ and $58 \%$ of the dataset thresholds. Small-scale processes seem to have a greater impact on precipitation in this region, maybe because of its steeper orography, smoothed by the model. Regarding Calabria and Central Italy, the E-OBS dataset is based on a few rain gauges and unlike in the other regions, the threshold in the dataset is lower than in both models. Flaounas et al. (2012) showed that E-OBS underestimates station rainfall extremes by 20 to $60 \mathrm{~mm}$ in coastal stations located in southern France. It is highly possible that this is also what is observed here.

A great advantage of nudged simulations is that the chronology of ERA-Interim is well respected and the downscaled HPEs can be dated. Table 4 shows the hit rates (HR) of the different simulations. The hit rate is calculated as the ratio of the number of events represented by the model and recorded in the reference dataset to the total number of events in the reference dataset. The target value of the hit rate is 1 , meaning that all the observed events are captured by the model.

The simulations show a hit rate larger than 0.4 for every region except Liguria for the comparison with high quality datasets. Prein et al. (2015a) also show that the intensity of the 97.5 percentile of precipitation in Liguria is underestimated by RCMs with $12.5 \mathrm{~km}$ and $50 \mathrm{~km}$ grid spacing respectively by $25 \%$ and $35 \%$ in SON. Again in Calabria (HR around 0.3) and even more in Central Italy (HR around 0.2), the scores are low but it is hard to attribute these deficiencies to the models or to the dataset since the dataset shows a lower threshold than the model and may not capture all the extreme events happening in these regions due to a low density of rain gauges. Flaounas et al. (2012) also show that the rainy days are not the same between E-OBS and independent rain gauges, which suggests low reliability in the selection of HPEs in these regions using E-OBS.

Given these HR, it is worth knowing whether or not the events that are identified as extreme in the models but not in the dataset are still HPEs. Table 5 shows the percentage of events represented by the model that are among the 100 largest events in the reference dataset. The scores larger than $70 \%$ and up to $88 \%$ show that most of the events that the models represent are actually events when intense precipitation occurred. Therefore in these regions, we can consider that RCMs are good enough for the study of HPEs. Liguria is the only region where the models do not seem to be able to represent HPEs correctly. Calabria and Central Italy also show weak results but it is not clear whether the errors comes from the models or from the dataset. Therefore, Calabria and Central Italy will be retained but Liguria will not be considered for the rest of the study.

\subsection{Representation of the submonthly variations of} $S S T$

In the previous section, the HPEs were selected throughout the year. However, in the dataset, $78 \%$ of the selected events occur from September to December. In the models, this figure is $71 \%$ in WRCPL, $74 \%$ in WDCPL and $70 \%$ in ALCPL. Therefore, the submonthly variations of SST are shown for this period. However, it is important to keep in mind that even though intense wind events are more frequent in winter (Chronis et al. 2011), submonthly variations of SST are stronger when the thermocline in the ocean is stronger and closer to the surface in summer and weaker when the thermocline is weaker and deeper in winter (Houpert et al. 2015). In Fig. 1, the root mean square (RMS) of the submonthly variations of SST is shown for each simulation or dataset. It is the RMS of the difference of the daily time 


\begin{tabular}{ccccccc}
\hline & Cévennes & Valencia & Calabria & Central Italy & Northeastern Italy & Liguria \\
\hline \hline ALCPL & 62 & 40 & 54 & 47 & 66 & 57 \\
dataset 50km & 117 & 56 & 26 & 36 & 119 & 91 \\
WRCPL & 114 & 90 & 100 & 81 & 103 & 90 \\
dataset 20km & 138 & 78 & 31 & 42 & 175 & 147 \\
\hline
\end{tabular}

Table 3. Threshold $\left(\mathrm{mm} \mathrm{day}^{-1}\right)$ used in simulations and in the regridded precipitation dataset on a 20 or $50 \mathrm{~km}$ grid to select the HPEs (Table 2 gives the rain dataset used for each region).

\begin{tabular}{ccccccc}
\hline & Cévennes & Valencia & Calabria & Central Italy & Northeastern Italy & Liguria \\
\hline \hline WRCPL & 0.48 & 0.46 & 0.23 & 0.25 & 0.44 & 0.18 \\
WRCTL & 0.44 & 0.48 & 0.20 & 0.30 & 0.44 & 0.18 \\
ALCPL & 0.41 & 0.41 & 0.27 & 0.30 & 0.48 & 0.24 \\
ALCTL & 0.47 & 0.42 & 0.23 & 0.36 & 0.41 & 0.20 \\
\hline
\end{tabular}

Table 4. Hit rate for every simulation between the 30 heaviest precipitation events in the simulation and the 30 heaviest precipitation events in the precipitation dataset regridded at each model resolution.

series of SST and a monthly smoothed time series during the period 1989-2012. All the panels show that the Mistral and Tramontane bring the strongest submonthly variability in the Mediterranean, with mean submonthly variations up to $0.4-0.6^{\circ} \mathrm{C}$ in the Gulf of Lions and the French Riviera. In addition, the Northern (or Liguro-Provencal) Current flows along the northern coasts from Liguria to Catalonia, and partly comes back to form the cyclonic gyre in the Gulf of Lions, partly cyclonically veers towards the Balearic coasts and partly goes on to the Alboran sea (Millot 1999). Its meanders and the appearance of anticyclonic eddies along the Catalan coast with lifespan of a few weeks are also responsible for the submonthly variability in the Ligurian sea, the Gulf of Lions and the Balearic sea (Garreau et al. 2011; Lebeaupin Brossier et al. 2014). Mistral/Tramontane winds also influence the Tyrrhenian SST submonthly variations together with the cyclonic eddy present off the Strait of Bonifacio (Millot 1999; Small et al. 2012), where submonthly variations reach 0.4 to $0.5^{\circ} \mathrm{C}$. The Adriatic sea shows mean variations of $0.4-0.5^{\circ} \mathrm{C}$ linked with the Bora wind. The Alboran sea also shows 0.3 to $0.5^{\circ} \mathrm{C}$ of submonthly variations, linked both with the presence of large eddies and to the Vandevales. All other regions show submonthly variations of 0.2 to $0.4^{\circ} \mathrm{C}$. To get an idea of the seasonal cycle of these variations, the submonthly variations of SST in the Gulf of Lions range from $1^{\circ}$ in summer to $0.4^{\circ}$ in winter (not shown).

The CNR dataset in Fig. 1a, which is a product especially designed for the Mediterranean sea, shows the strongest amplitude of submonthly variations among all the datasets (CNR, OSTIA and ERAInterim). It is stronger by $0.1^{\circ} \mathrm{C}$ compared to OSTIA (Fig. 1b) in all the considered regions and shows a thinner spatial structure than OSTIA, though the global pattern is similar. ERA-Interim (Fig. 1e), used in all CTL simulations fails to capture the fine scale structure and the amplitude of the submonthly variations.
The two CPL simulations WRCPL (Fig. 1c) and ALCPL (Fig. 1d) show coherent spatial structures with OSTIA and CNR with the effect of Mistral/Tramontane, the Bora and Vandevales. However, their intensity is closer to OSTIA than to CNR. They both seem to underestimate submonthly variations in the southern part of the Mediterranean, notably in the Ionian sea by $0.1 \mathrm{tp} 0.2^{\circ} \mathrm{C}$. ALCPL shows better ability to reproduce the submonthly variations in the Gulf of Lions than WRCPL in this season.

The models perform reasonably well in representing HPEs in the Cévennes, Valencia and Northeastern Italy (Calabria and Central Italy can not be well evaluated) and submonthly variations of SST in the western Mediterranean basin, although they tend to underestimate them. Therefore, they are a valuable tool to study the impact of submonthly variations of SST on heavy rain events in these regions.

\section{Response of HPEs to variations in SST}

The approach used to identify whether or not the HPEs selected in the simulations were sensitive to changes in the SST is to compare the different simulations that were run for each model. In fact, the nudging technique applied to the model allows the large scale fields above the boundary layer to respect the ERA-Interim fields so that simulations with different surface conditions still have the same large scale fields but differ from the boundary layer response. Tables 4 and 5 confirm these results with similar HRs between CTL and CPL simulations. In order to get synthetic indexes of SST and rain differences, the methodology developed in Berthou et al. (2014) is adopted. A zone of precipitation differences of 60000 to $65000 \mathrm{~km}^{2}$ is defined around the zone where extreme events were selected for each region (blue boxes in Fig. 4). It corresponds to the zone encompassing most intense precipitation that occurred among the selected events as shown by the occurrences of precipitation greater than $50 \mathrm{~mm}$ (blue contours in Fig. 4). 


\begin{tabular}{lccccccc}
\hline & Cévennes & Valencia & Calabria & Central Italy & Northeastern Italy & Liguria \\
\hline \hline & & & & & & & \\
WRCPL & 88 & 81 & 47 & 41 & 87 & 41 \\
WRCTL & 88 & 77 & 43 & 45 & 82 & 45 \\
ALCPL & 85 & 70 & 39 & 53 & 71 & 39 \\
ALCTL & 81 & 69 & 52 & 41 & 70 & 34 \\
\hline
\end{tabular}

Table 5. Percentage of events represented by the model that are among the 100 largest events in the reference dataset

Eq. (1) shows the calculation to define the $I_{\text {rain }}$ index that measures precipitation difference between two simulations in the box previously defined. It is the spatial RMSE between two simulations in a certain zone and allows dipoles of precipitation differences not to each other cancel out.

$$
I_{\text {rain }}=\sqrt{{\overline{\delta P^{2}}}^{\text {Reg } g_{\text {Precip }}}}
$$

where $\delta P$ represents the daily precipitation difference between two simulations (CPL-CTL or CPL-SMO) and Reg $g_{\text {Precip }}$ names the zone on which the spatial average is performed, i.e. the zone defined in blue in Fig. 4.

The same method is used for the SST in an area upstream of the precipitation event, defined as a function of the upstream low-level jets for each zone. The zones are shown in Fig. 4 with a thick red line. They are defined as the zones where most occurrences of winds larger than $10 \mathrm{~m} \mathrm{~s}^{-1}$ are located, i.e. where most low-level jets feeding the events are located. The longest dimensions of these zones are between $550 \mathrm{~km}$ and $800 \mathrm{~km}$, which means a residence time in the zone of the order of 15 to $22 \mathrm{~h}$ with a low-level wind speed of $10 \mathrm{~m} \mathrm{~s}^{-1}$. Flux differences between simulations can therefore be large and last for half a day under this low-level jet. Thus, the hypothesis based on the work of Berthou et al. (2014) is that these zones influence the low-level jet dynamics through the generation of pressure anomalies and stratification changes arising from changes in surface fluxes colocalised with SST changes. For Central Italy, either the zone in the Adriatic sea or in the Tyrrhenian sea (Fig. 4) is used depending on the direction of the incoming flow (in ALCPL about $60 \%$ and in WRCPL about $50 \%$ of the events come from the Adriatic sea).

Berthou et al. (2014) showed the efficiency of taking a SST difference index as defined in Eq. (2).

$$
I P S S=\sqrt{\overline{\delta S S T^{2}} \text { Reg }_{S S T}}
$$

where $\delta S S T$ represents the mean daily SST differences on the day of the HPE between two simulations (CPLCTL or CPL-SMO) and $\operatorname{Reg}_{S S T}$ is the zone on which the average is performed, i.e. the zone outlined in red in Fig. 4.

Since these indexes are sensitive to the model resolution, the precipitation and SST fields of WRF at $20 \mathrm{~km}$ resolution were regridded on ALADIN grid at $50 \mathrm{~km}$ resolution before the calculations.

In Fig. 5 and Fig. 6, $\mathrm{I}_{\text {rain }}$ divided by $\mathrm{P}_{\max }$ (the daily precipitation maximum in the rain box in the model) is plotted against the IPSS. This relative $\mathrm{I}_{\text {rain }}$ (refered as $i_{\text {rain }}$ from now on) allows the comparison between models which do not produce the same maximum precipitation intensity. Each cross is a single event for CPL-CTL in Fig. 5 and CPL-SMO in Fig. 6 respectively. CPL-CTL (Fig. 5) shows changes of SST due to multiple effects, the dominant one being the different SST climatology between the coupled model and ERA-Interim since the coupled model has no assimilation of observed SST. CPL-SMO (Fig. 6) shows the effect of SST changes arising from submonthly coupled effects (in this region, mainly changes due to Mistral and Tramontane wind regimes).

The figures for the Cévennes (Fig. 5a and Fig. 6a) show similar results as in (Berthou et al. 2014) for WDCPL-WDCTL and WDCPL-WDSMO: the changes in precipitation amounts are proportional to the changes in SST in the model (the Pearson correlation coefficients are shown in Table 6). The submonthly coupled effects are weaker than changes of climatology (IPSS up to $1.2^{\circ} \mathrm{C}$ for CPL-SMO vs $2^{\circ} \mathrm{C}$ for CPLCTL) but can still show a relative $i_{\text {rain }}$ of 0.085 . The slope for ALCPL-ALCTL is also present and robust (Table 6) and it is similar to the WDCPL-WDCTL one (Fig. 5a). The same calculations for WRCPL-WRCTL show a less robust slope (Table 6) with smaller IPSS values due to smaller SST biases in the model for this region but the slope is still similar to WDCPLWDCTL. It is worth noting at this point that SST biases in WDCPL are much larger than in WRCPL, allowing the examined statistical relationship to be extended to include larger IPSS values for the Cévennes and Valencia areas.

This study also extends the study carried out in Berthou et al. (2014) to other regions than the Cévennes. Fig. 5 and Table 6 show that linear relationships between IPSS and the relative $i_{\text {rain }}$ are obtained by both models in Valencia and Calabria together with the Cévennes. Central Italy shows a more random sensitivity to IPSS. Fig. 4d shows the two zones used in Central Italy to calculate the IPSS: one in the Adriatic when the wind feeding the precipitation system comes from this region and one in the Tyrrhenian sea when the incoming lowlevel jet is westerly. The two different symbols for the HPEs fed by these two different zones do not show more sensitivity from one zone compared to the other. Therefore, SST variations in these upstream zones may not have a direct effect on precipitation in Central Italy. Northeastern Italy shows a weak sensitivity to SST changes in all models except for a few events. The upstream trajectory of the low level jet is mixed between land and sea due to the configuration of the region. Therefore, the Adriatic sea seems to have a weak effect on precipitation in most cases. 
a. Cévennes

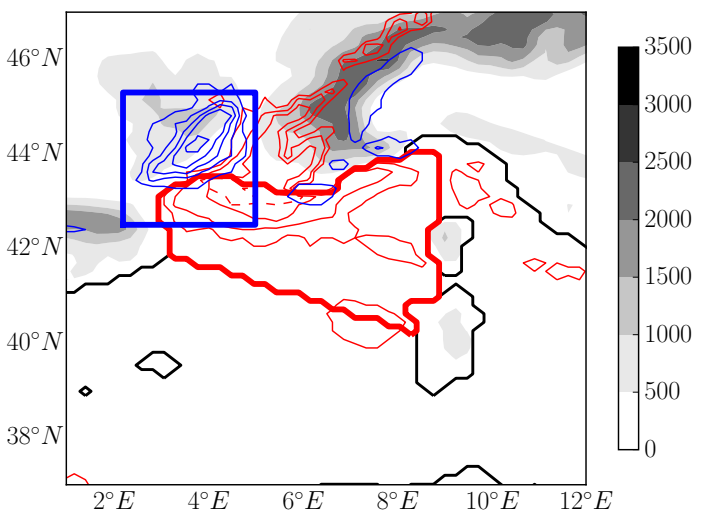

c. Calabria

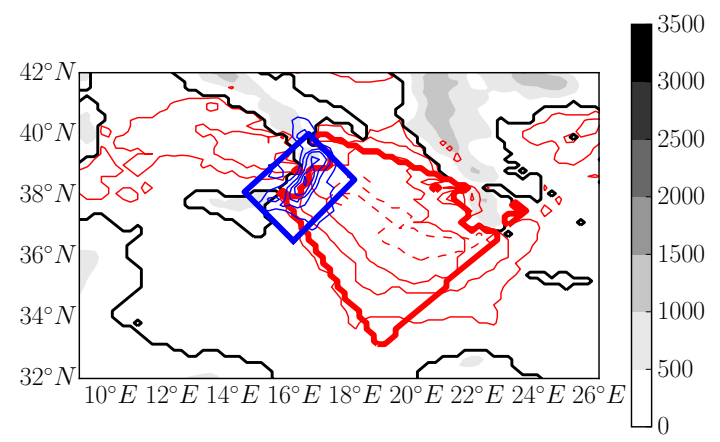

e. Northeastern Italy b. Valencia

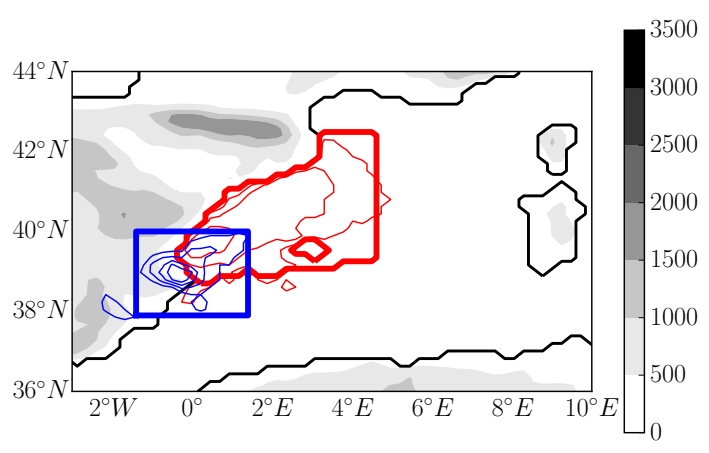

d. Central Italy

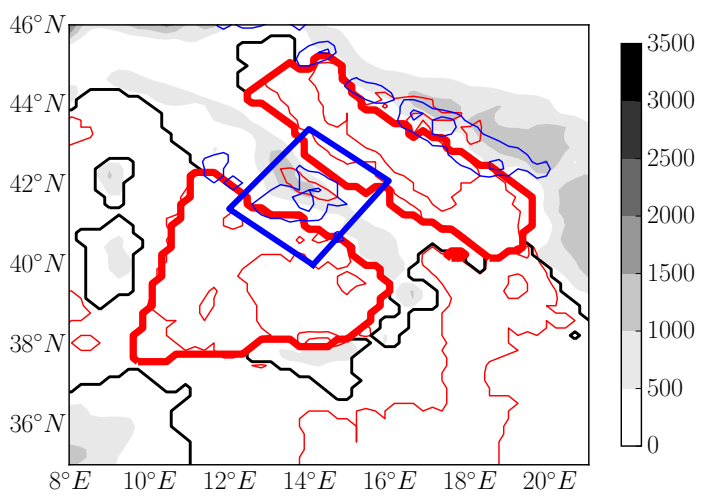

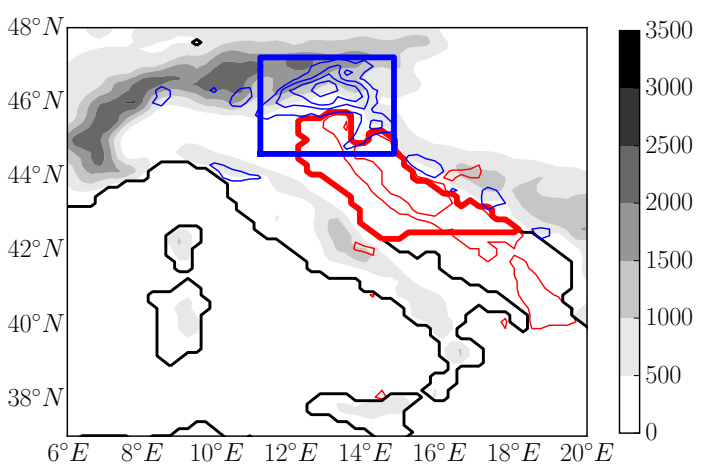

Figure 4. In blue contours: occurences of daily rain greater than $50 \mathrm{~mm}$ among the selected events, contour every 5 occurrence. In red contours (resp. dashed red contours): occurrences of surface wind intensity larger than $10 \mathrm{~m} \mathrm{~s}^{-1}\left(\right.$ resp. $15 \mathrm{~m} \mathrm{~s}^{-1}$ ) among the selected events, contour every 5 occurrence, first contour for 15 occurrences. Total number of events is around 30 (selected with the thresholds presented in Table 3). The box in thick blue lines shows the zone selected for calculating the rain differences between simulations $\left(I_{\text {rain }}\right)$ and the box in thick red lines shows the zone selected for calculating the SST differences between simulations (IPSS). Results are shown for WRCPL.

Looking specifically at the sensitivity of HPE to submonthly variations of SST in Fig. 6 using CPL$\mathrm{SMO}$, we can conclude from this study that the Cévennes, Valencia and Calabria show a robust relation between relative $i_{\text {rain }}$ and IPSS. The slopes are stronger in Valencia and Calabria than in the Cévennes: an IPSS of $0.5^{\circ} \mathrm{C}$ leads to a relative $\mathrm{i}_{\text {rain }}$ of about 0.08 (against 0.04 for the Cévennes). Valencia is the region with the strongest IPSS and the strongest relative changes in precipitation (up to 0.30). Calabria, though presenting a similar slope, shows weaker IPSS in the Ionian sea. In Central Italy, the relation is more random, as 
a. Cévennes

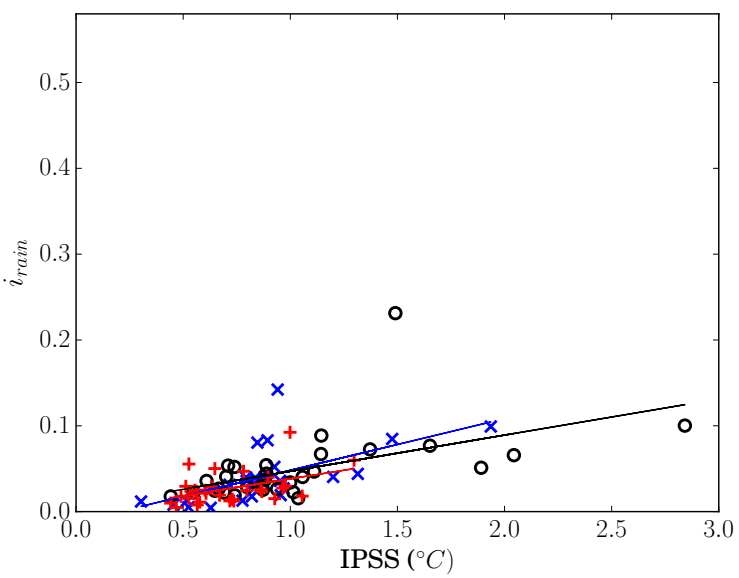

c. Calabria

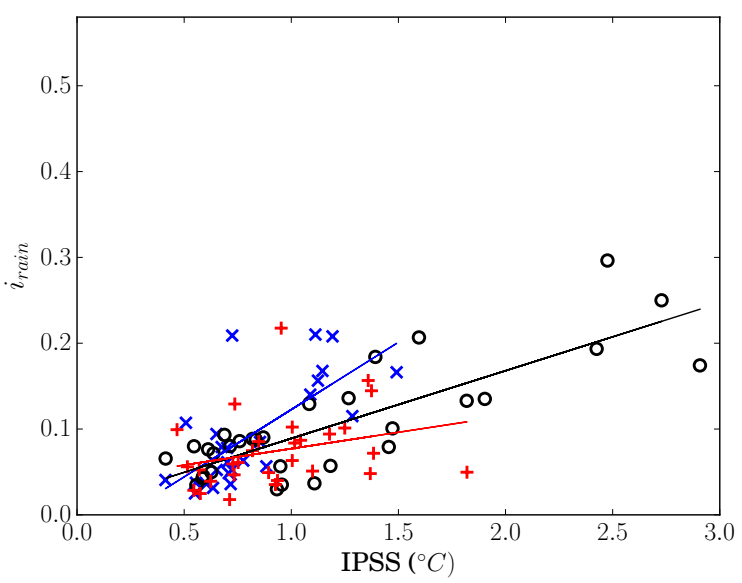

e. Northeastern Italy

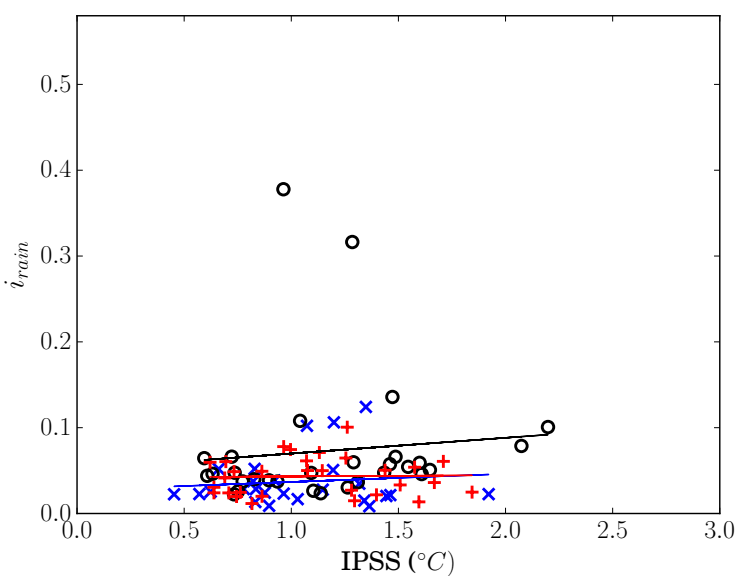

b. Valencia

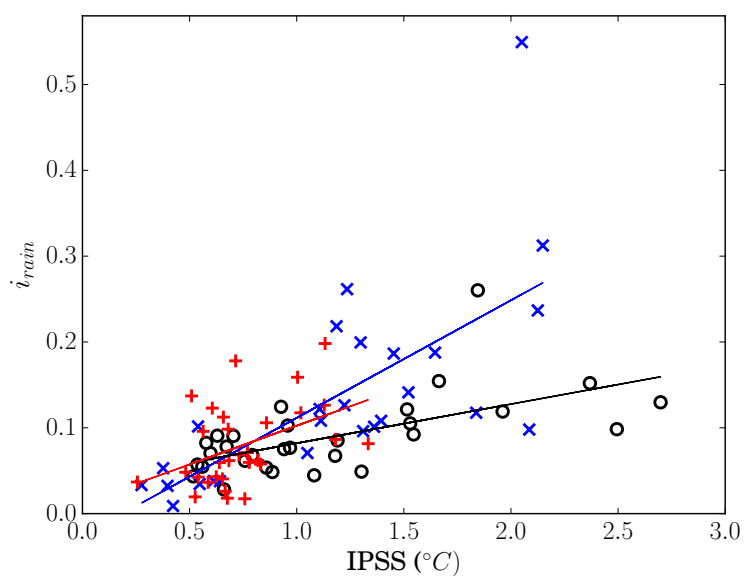

d. Central Italy

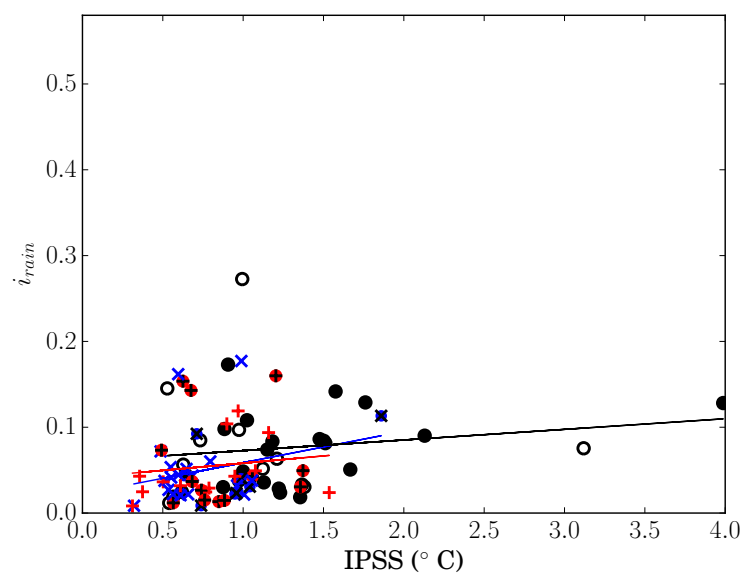

Figure 5. Relative $i_{\text {rain }}$ calculated for every event in the zone named above each pannel and plotted against the index of SST differences in the corresponding SST zone for WDCPL-WDCTL (blue x crosses), WRCPL-WRCTL (red + crosses), ALCPLALCTL (black circles). Each cross is one event as selected in Table 3.

its was for CPL-CTL. Northeastern Italy shows very weak sensitivity of precipitation to SST submonthly variations.

Sensitivity of the results to the choice of boxes was tested for the Cévennes region in Berthou et al.
(2014) and the relationship was shown to be robust for locations of the SST box down to the Balearic Islands. Several tests on the shape of precipitation and SST zones within the regions where they are defined were 
a. Cévennes

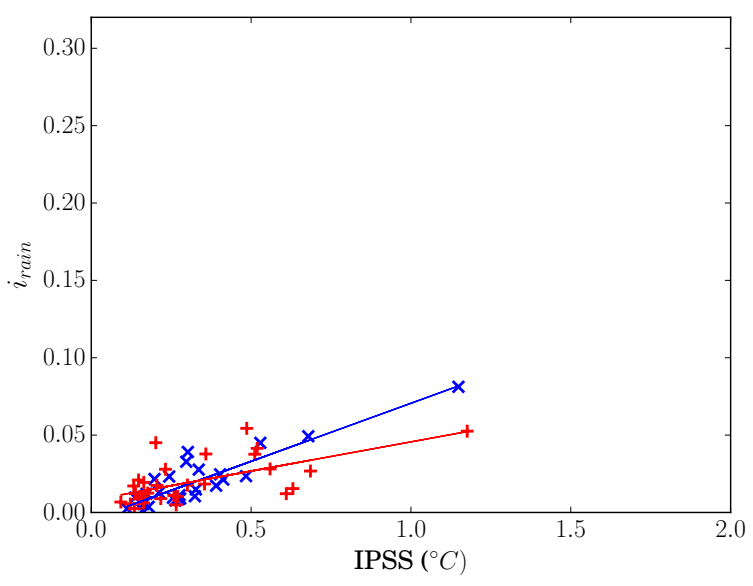

c. Calabria

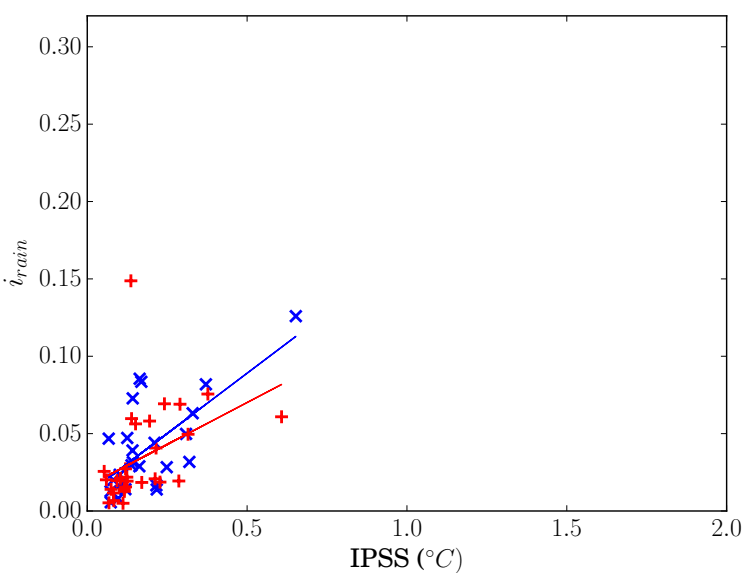

e. Northeastern Italy

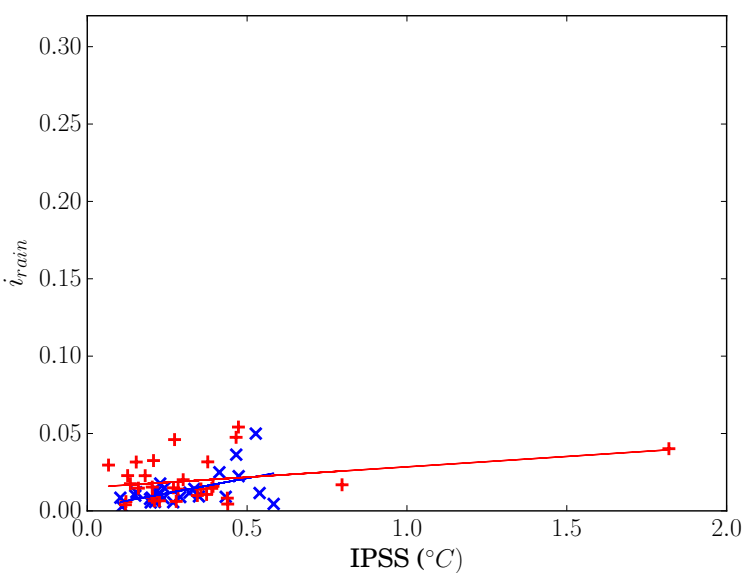

b. Valencia

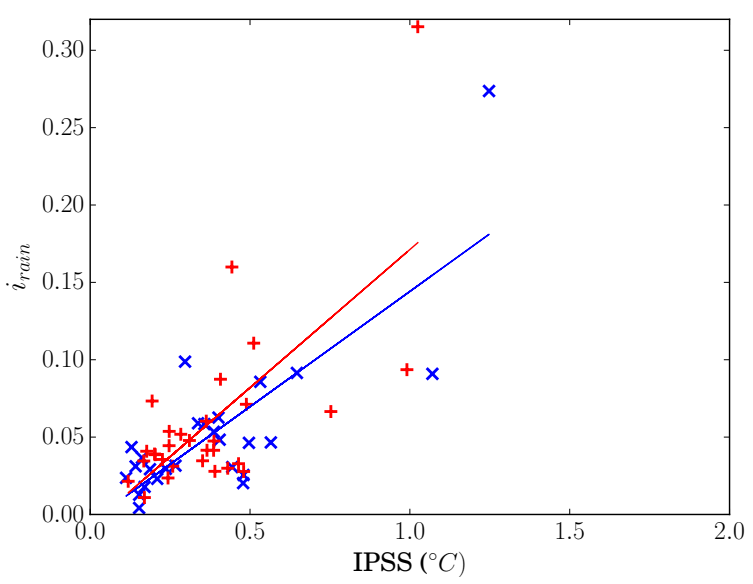

d. Central Italy

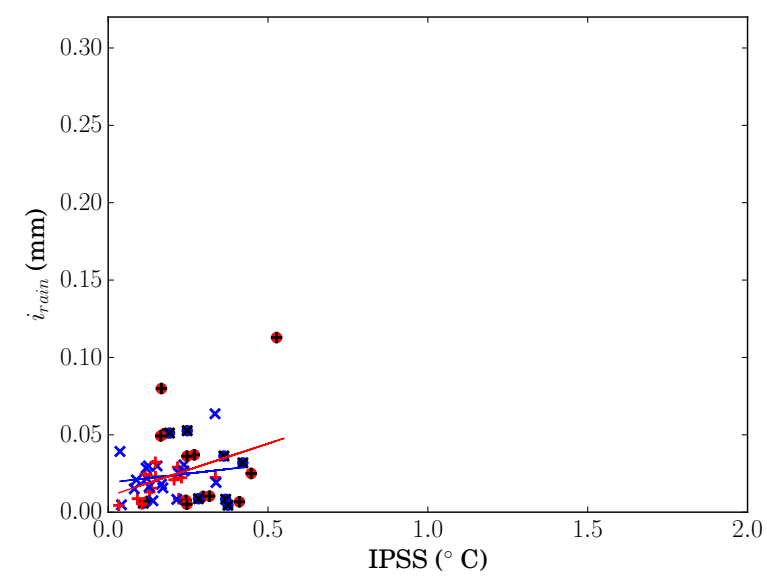

Figure 6. Same as Fig. 5 for WDCPL-WDSMO (blue x crosses), WRCPL-WRSMO (red + crosses). Note the scale difference.

done with no loss of robustness in the relationship (not shown).

The events were selected throughout the year with no preferable season, though more than $70 \%$ occur from September to December. There is no evident difference of sensitivity to the SST between events in different seasons: less numerous, the points out of the main season are no outliers in the plots (not shown).

4.1. Wind changes are mainly responsible for precipitation changes

\section{Changes in moisture convergence.}




\section{Cévennes Valencia Calabria Central Italy Northeastern Italy}

$\begin{array}{llllll}\text { WDCPL-WDSMO } & \mathbf{0 . 8 9} & \mathbf{0 . 7 9} & \mathbf{0 . 6 7} & 0.16 & \mathbf{0 . 5 1} \\ \text { WDCPL-WDCTL } & \mathbf{0 . 6 0} & \mathbf{0 . 6 9} & \mathbf{0 . 7 1} & 0.26 & 0.11 \\ \text { ALCPL-ALCTL } & \mathbf{0 . 7 1} & \mathbf{0 . 6 1} & \mathbf{0 . 8 2} & 0.16 & 0.10 \\ \text { WRCPL-WRSMO } & \mathbf{0 . 6 2} & \mathbf{0 . 6 8} & 0.41 & 0.38 & 0.31 \\ \text { WRCPL-WRFCTL } & 0.45 & 0.44 & 0.28 & 0.13 & 0.02\end{array}$

Table 6. Pearson correlation coefficients R calculated between relative $i_{\text {rain }}$ and IPSS $\left({ }^{\circ} \mathrm{C}\right)$ (defined in Eq. (2)) with IPSS calculated on the different regions defined in Fig. 2. Statistically significant coefficients of correlation above $99 \%$ using a Student-t test are indicated with bold font.

Berthou et al. (2014, 2015) showed in two case studies that the mechanisms linking SST differences to precipitation differences did not come directly from changes in the air moisture that could change the precipitation amount but from changes in the wind dynamics that were responsible for the convergence of moisture. Three mechanisms were highlighted: changes in SST imply changes in surface fluxes under the low-level jet, which results in convergence of temperature anomalies, themselves responsible for pressure anomalies in the convergence zone that can shift the place of this convergence zone where precipitation occur. The two other mechanisms are linked with changes in stratification of the incoming flow. This can change the intensity of the flow deviation by high orography. Changes in stratification can also change the dynamics of the low-level convergence, that can also be shifted through this mechanism. These mechanisms were highlighted for case studies in the Cévennes region but the results of this study (other regions also present similar linear relationships between changes in rain and changes in SST in the upstream region) raises the question of whether or not changes in precipitation are also explained by wind changes rather than by changes of the moisture content of the low-level jet in all regions and models.

To answer this question, we computed the low-level moisture convergence in the precipitation zone as such:

$$
M_{\text {cvg }}^{X}=-\nabla\left(\mathbf{u}_{X} Q_{X}\right)
$$

where $X$ stands for the simulation name (CPL or $\mathrm{CTL}), \mathbf{u}$ is the daily-mean vector of near-surface horizontal wind, $Q$ is the daily-mean near-surface specific humidity field. Then, the same kind of index is computed as for the rain or SST:

$$
I_{M}=\sqrt{{\overline{\left(M_{c v g}^{C P L}-M_{c v g}^{C T L}\right)^{2}}}^{R e g_{S S T}}}
$$

This $I_{M}$ shows the amount of difference in moisture convergence between the two simulations CPL and CTL.

In order to identify whether or not changes in moisture or changes in the wind are the dominant part of the changes in the moisture convergence, we compute $M_{\text {cvg }}$ while keeping one of the fields: $\mathbf{u}$ or $Q$ from the CTL simulation:

$$
\begin{aligned}
& M Q=-\nabla\left(\mathbf{u}_{C T L} Q_{C P L}\right) \\
& M U=-\nabla\left(\mathbf{u}_{C P L} Q_{C T L}\right)
\end{aligned}
$$

From these two new variables, we compute two new indexes:

$$
\begin{aligned}
& I U=\sqrt{{\overline{\left(M_{c v g}^{C P L}-M Q\right)^{2}}}^{\operatorname{Reg}_{S S T}}} \\
& I Q=\sqrt{{\overline{\left(M_{c v g}^{C P L}-M U\right)^{2}}}^{\text {RegSST }}}
\end{aligned}
$$

These two indexes show the intensity of the moisture convergence change when only the wind field changes $(I U)$ or when only the moisture field changes $(I Q)$. Finally, these ratios are calculated:

$$
\begin{aligned}
& U_{c h g}=I U / I_{M} \\
& Q_{c h g}=I Q / I_{M}
\end{aligned}
$$

The closer to 1 that these ratios are, the larger their contribution to changes in the moisture convergence field between CPL and CTL is. Table 7 shows that in all the regions and for both models, Uchange is close to 0.9 while Qchange is closer to $0.20-0.30$. This means that the changes in moisture convergence are clearly linked with wind changes in WRF and ALADIN models rather than to moisture changes in the lower atmosphere. From this, we can infer that the precipitation changes are most probably caused by wind changes than moisture changes in all the regions for WRF and ALADIN, which is consistent with the mechanisms identified in Berthou et al. (2015).

Table 8 further explains why the rain differences arise from wind changes rather than moisture changes. Nearsurface relative humidity in the upstream region above the sea reaches values greater than $75 \%$. This is in line with the 10 cases studied by Duffourg and Ducrocq (2011) in the Cévennes and is common to all the regions studied. The air is already almost saturated with moisture and the moisture fluxes occurring in this zone do not change the moisture content much. The wind changes are most probably linked with temperature changes.

\section{Changes in surface heat fluxes.}

We now investigate the surface heat fluxes in order to understand better the link between SST changes and precipitation changes. Table 9 shows the daily mean and standard deviation of surface heat fluxes for each zone. Even though the relative humidity is high (Table 8), latent heat fluxes are always larger than sensible heat fluxes by at least a factor of 3 . The Cévennes and Northearn Italy show the lowest mean sensible (less than $10 \mathrm{~W} \mathrm{~m}^{2}$ ) and latent heat fluxes 


\begin{tabular}{lccccc}
\hline & Cévennes & Valencia & Calabria & Central Italy & Northeastern Italy \\
\hline \hline & & & & & \\
$U_{c h g}$ WDCPL-WDCTL & $0.86(0.11)$ & $0.95(0.07)$ & $0.92(0.05)$ & $0.96(0.03)$ & $0.86(0.13)$ \\
$Q_{c h g}$ WDCPL-WDCTL & $0.32(0.16)$ & $0.23(0.10)$ & $0.21(0.07)$ & $0.22(0.09)$ & $0.32(0.18)$ \\
\hline \hline & & & & & \\
$U_{c h g}$ WRCPL-WRCTL & $0.84(0.12)$ & $0.95(0.04)$ & $0.93(0.05)$ & $0.94(0.05)$ & $0.91(0.07)$ \\
$Q_{c h g}$ WRCPL-WRCTL & $0.39(0.14)$ & $0.23(0.09)$ & $0.19(0.07)$ & $0.28(0.12)$ & $0.30(0.15)$ \\
\hline \hline & & & & & \\
$U_{c h g}$ ALCPL-ALCTL & $0.88(0.10)$ & $0.90(0.06)$ & $0.90(0.08)$ & $1.02(0.18)$ & $0.87(0.12)$ \\
$Q_{c h g}$ ALCPL-ALCTL & $0.28(0.12)$ & $0.30(0.13)$ & $0.29(0.14)$ & $0.38(0.21)$ & $0.28(0.16)$ \\
\hline
\end{tabular}

Table 7. Mean for all events (and standard deviation) of $U_{c h g}$ (ratio of moisture convergence change when only the wind field changes) and $Q_{c h g}$ (ratio of moisture convergence change when only the moisture field changes) as defined by equations Eq. (9) and Eq. (10).

\begin{tabular}{lccccc}
\hline & Cévennes & Valencia & Calabria & Central Italy & Northeastern Italy \\
\hline \hline WDCPL & $85(5)$ & $81(8)$ & $78(4)$ & $81(6)$ & $81(6)$ \\
WRCPL & $83(4)$ & $79(6)$ & $79(5)$ & $77(5)$ & $80(6)$ \\
\hline
\end{tabular}

Table 8 . Mean $2 \mathrm{~m}$ relative humidity (and standard deviation) (\%) in the SST upstream zone (\%)

(around $100 \mathrm{~W} \mathrm{~m}^{2}$ ) in the upstream regions. Calabria shows the largest mean sensible $\left(43 \mathrm{~W} \mathrm{~m}^{2}\right)$ and latent heat fluxes $\left(207 \mathrm{~W} \mathrm{~m}^{2}\right)$ followed by Valencia and Central Italy. Note that these fluxes are much weaker than heat fluxes occurring with the Mistral blowing from the continent over the ocean which can be larger than $500 \mathrm{~W} \mathrm{~m}^{2}$ (Flamant 2003; Lebeaupin Brossier and Drobinski 2009). In order to assess the changes in surface heat flux, a similar index as the ones for precipitation and SST is calculated: the spatial RMSE of the mean daily heat fluxes between CPL and CTL on the one hand and between CPL and SMO on the other, called $I_{L H}$ for the latent heat flux and $I_{S H}$ for the sensible heat flux. Fig. 7 and Fig. 8 show the results. In both differences, between CPL and CTL and CPL and SMO, changes in latent heat fluxes dominate the response to IPSS with a slope between $I_{L H}$ and IPSS about 4 times larger than between $I_{S H}$ and IPSS in all cases. Table 10 shows the robust relationship between $I_{L H}$ and IPSS (slopes are not as robust for $I_{S H}$, not shown), showing the presumable role of latent heat flux in the relationship between rain changes and SST changes. However, $I_{S H}$ also show sensitivty to the IPSS and may also play a role.

Moreover, it shows that for Central Italy and Northeastern Italy, a robust relationship of the latent heat flux to the IPSS is also found whereas no robust relationship is found between $i_{\text {rain }}$ and IPSS. These changes in the heat fluxes do not linearly impact the precipitation events over Central Italy and Northeastern Italy as discussed before.

The Cévennes show weaker fluxes and weaker sensitivity of fluxes to the IPSS, possibly leading to the weaker sensitivity of precipitation changes to IPSS compared to Valencia and Calabria. This different sensitivity could also be linked with different mechanisms linking SST changes with rain changes. Calabria and Spain show similar sensitivity of $I_{L H}$ to the IPSS and of $i_{\text {rain }}$ to the IPSS.

\section{Quality and use of the IPSS without CPL-SMO simulations for the precipitation}

\subsection{IPSS in datasets based on observations}

In the previous section, we investigated the effects of both CPL-CTL and CPL-SMO differences. The aim of examining the CPL-CTL difference was to investigate the effect of changes of SST that can be quite large (up to IPSS of $4.0^{\circ} \mathrm{C}$ for ALADIN and up to $2.1^{\circ} \mathrm{C}$ for WRF for single events) on precipitation. However, those differences are not easy to discuss physically since they arise from the monthly update of CTL SST for ALADIN, from the climate models biases that accumulate over the long term and also from the proper coupling effects of the atmosphere with the ocean. These simulations were useful in assessing the impact of relatively large changes of SST on heavy rain. However, the SMO simulations were computed to get physically relevant SST differences that do arise from the coupling of the atmosphere with the ocean at temporal scales smaller than a month. However, it is legitimate to wonder if variations of SST at submonthly time scales are realistic. Section 3 has shown a good ability of the models to represent the September to December climatological spatial distribution of submonthly variations of SST, though they tend to underestimate the intensity especially compared to the CNR datatset. The aim of this section is to check if the models are able to reproduce the submonthly variations of SST when HPEs occur. If it is the case, we can build an IPSS index with the observations in the regions of interest to evaluate when submonthly coupling can impact HPEs.

Two products of optimal interpolation, a global one (OSTIA SST) and a regional one (CNR SST), are used for the comparison with the models (section 2.3). The IPSS is calculated for each dataset in the same way that the IPSS for the CPL-SMO simulation is computed. First, the time series of SST is smoothed over a month 


\begin{tabular}{lccccc}
\hline & Cévennes & Valencia & Calabria & Central Italy & Northeastern Italy \\
\hline \hline WDCPL SH & $8(25)$ & $49(38)$ & $47(40)$ & $49(93)$ & $8(19)$ \\
WDCPL LH & $88(39)$ & $192(84)$ & $229(79)$ & $173(120)$ & $111(53)$ \\
WRCPL SH & $3(23)$ & $43(38)$ & $41(37)$ & $30(47)$ & $1.7(16)$ \\
WRCPL LH & $82(39)$ & $187(84)$ & $207(77)$ & $158(83)$ & $102(55)$ \\
\hline \multicolumn{7}{c}{ Table 9. Mean (and standard deviation) of LH and SH in the SST upstream zone $\left(\mathrm{W} \mathrm{m}^{-2}\right)$}
\end{tabular}

\begin{tabular}{lccccc}
\hline & Cévennes & Valencia & Calabria & Central Italy & Northeastern Italy \\
\hline \hline & & & & & \\
WDCPL-WDSMO & $\mathbf{0 . 9 5}$ & $\mathbf{0 . 9 5}$ & $\mathbf{0 . 9 4}$ & $\mathbf{0 . 7 1}$ & $\mathbf{0 . 6 8}$ \\
WDCPL-WDCTL & $\mathbf{0 . 9 0}$ & $\mathbf{0 . 8 3}$ & $\mathbf{0 . 6 8}$ & $\mathbf{0 . 8 8}$ & $\mathbf{0 . 5 8}$ \\
WRCPL-WRSMO & $\mathbf{0 . 9 4}$ & $\mathbf{0 . 8 7}$ & $\mathbf{0 . 9 1}$ & $\mathbf{0 . 8 5}$ & $\mathbf{0 . 7 7}$ \\
WRCPL-WRCTL & 0.40 & 0.39 & $\mathbf{0 . 4 9}$ & $\mathbf{0 . 8 6}$ & 0.45
\end{tabular}

Table 10. Pearson correlation coefficients $\mathrm{R}$ calculated between $I_{L H}\left(\mathrm{~W} \mathrm{~m}^{-2}\right)$ and IPSS $\left({ }^{\circ} \mathrm{C}\right)$. Statistically significant coefficients of correlation above $99 \%$ using a Student-t test are indicated with bold font.

around the event date, as for SMO simulation.. Then, the IPSS is computed in this way:

$$
I P S S_{d t}=\sqrt{\overline{\left(S S T_{d t}-\left[S S T_{d t}\right]^{m t h}\right)^{2}} \operatorname{Reg}_{S S T}}
$$

where "dt" stands for OSTIA or CNR dataset and $[-]^{m t h}$ shows the 31 day average centered on the day of the event. These "observed" IPSS can then be compared with the simulated IPSS. There is no SMO simulation for ALADIN but such IPSS can also be calculated in the way described by Eq. (11) from the ALADIN CPL SST. It is equivalent to the IPSS calculated between CPL and SMO simulations. Fig. 9 and Table 11 show the IPSS comparison.

The Cévennes upstream region shows good agreement in IPSS between both datasets and between WD and the datasets (Fig. 9a). Table 11 confirms the results, with high correlation coefficients for ALADIN (0.78-0.79), WR (0.77-0.84) and WD (0.75-0.84). Therefore, we can be more confident in the results for the Cévennes: WD and WR are able to reproduce quite well the variations of SST due to Mistral/Tramontane winds and to the recovery of the ocean mixed layer after such episodes in the Gulf of Lions and down to Sardinia.

In the upstream region of Valencia (i.e. the Balearic Sea), the agreement between CNR and OSTIA datasets is not as good with correlations of $0.65-0.75$. The correlations between models and datasets are also of the same order. However, the correlations are still significant: we can conclude that the models are also able to represent submonthly variations linked to the Cierzo, Tramontane and Mistral or to Catalan eddies in this region, although the conclusion is not as strong as in the Cévennes upstream region.

The Calabria upstream region shows weaker variations in the model and in the datasets: most of the data is confined below $0.5^{\circ} \mathrm{C}$ in Fig. 9c. The effects of the Gregale and Sirocco seem to be weaker on SST submonhtly variations. However, we showed in the previous part that such variations were strong enough in this region to generate rain anomalies.
Table 11 shows that the correlation between CNR and OSTIA is not strong in this region (between 0.32 and 0.62 among the three sets of events). The models also agree less with the datasets. WDCPL shows better agreement with OSTIA while ALCPL agrees better with CNR. Fig. 9 shows that WDCPL tends to underestimate submonthly variations by 0.1 to $0.5^{\circ} \mathrm{C}$ in the region compared to the datasets, with larger underestimation compared to CNR. It is hard to evaluate the submonthly variations of models with such disagreement among the datasets. However, these regions should deserve particular attention regarding the impact that SST has on HPEs in RCMs.

The IPSS in Central Italy is calculated either with the box in the Adriatic or in the Tyrrhenian sea depending on the direction of the incoming flow (Fig. 4). The models show reasonable agreement with the datasets. So do the datasets together.

The IPSS of Northeastern Italy computed over the Adriatic sea shows a weak agreement between OSTIA and CNR (0.10) for WD. The very strong Pearson correlation coefficient for $\mathrm{WR}$ is again given by one outlier with an IPSS of $1.9^{\circ} \mathrm{C}$. Once removed, the correlation is very weak (below 0.16) between the datasets and between the model and each dataset. ALADIN shows better agreement but it is still not very conclusive. We can infer from these results that the submonthly variations of SST in the Adriatic sea are very variable among the datasets and the models, so that no proper agreement is reached, either between the datasets or between each model and each dataset. However, this is not critical for HPEs since they are weakly sensitive to those variations (Fig. 5e).

\subsection{Which HyMeX SOP1 events were sensitive to submonthly air-sea coupling?}

This article allowed us to identify three regions among the six HyMeX regions most hit during HyMeX SOP 1 that are sensitive to SST changes in the upstream region where the low-level jets feeding the event blow: the Cévennes, Valencia and Calabria. Now that a relationship has been built between $I_{\text {rain }} / P_{\max }$ and 


\section{a. Cévennes}

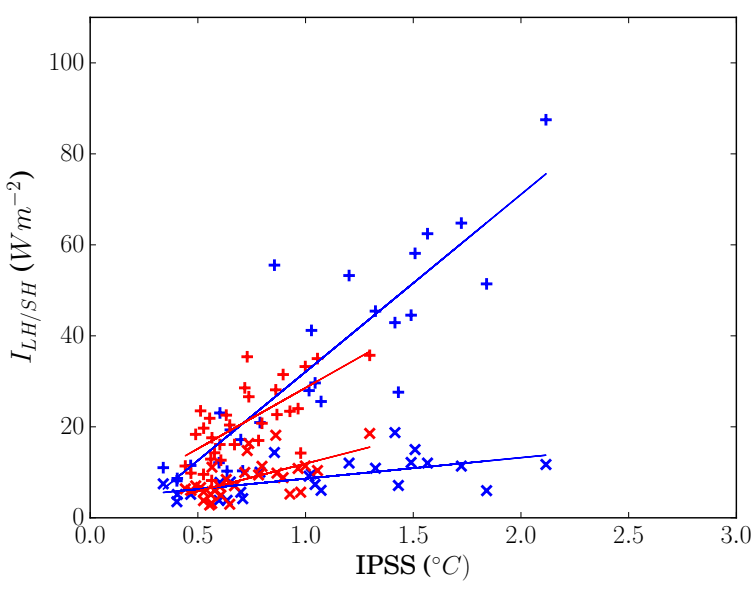

c. Calabria

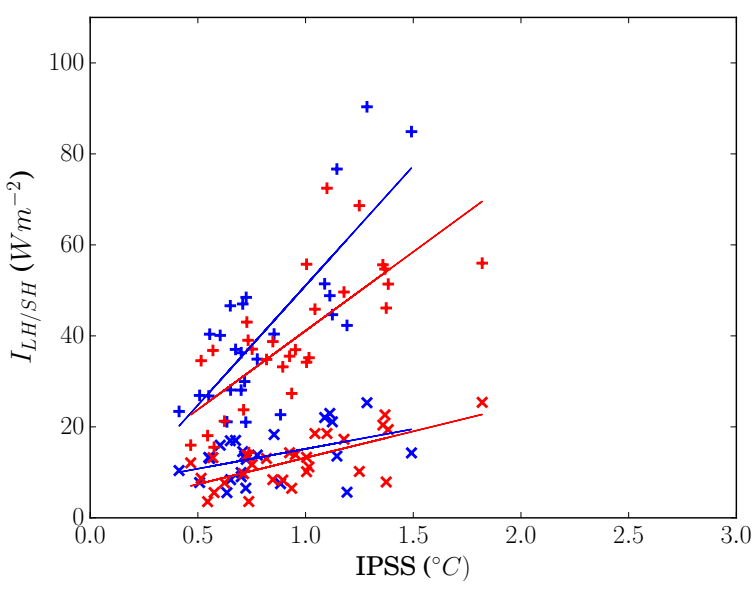

e. Northeastern Italy

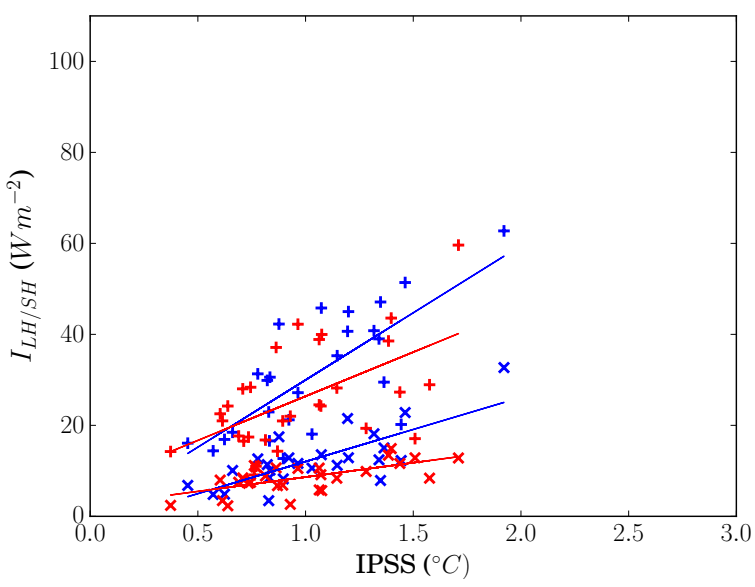

b. Valencia

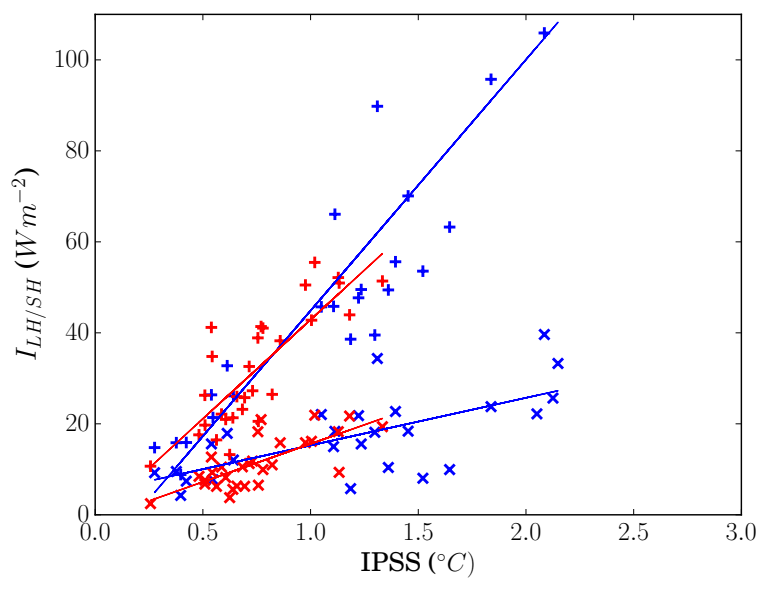

d. Central Italy

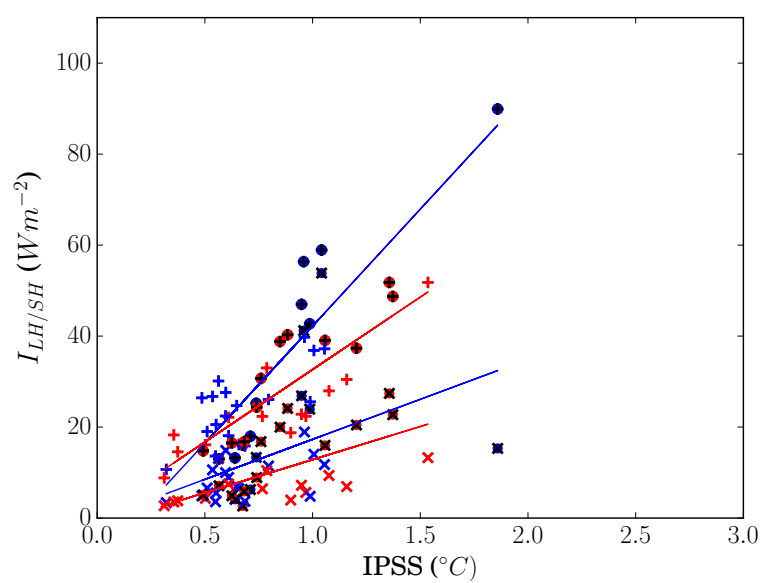

\begin{tabular}{|c|c|c|c|}
\hline \multirow[b]{2}{*}{ LH WDCPL-WDCTL } & \multirow{2}{*}{$\begin{array}{c}\mathbf{a}, \mathbf{b}, \mathbf{c}, \mathbf{e}: \\
+\end{array}$} & \multicolumn{2}{|c|}{$\begin{array}{l}\text { d: } \\
\text { Low-level jet from Low-level jet from } \\
\text { the Tyrrhenian sea } \text { the Adriatic sea }\end{array}$} \\
\hline & & + & - \\
\hline LH WRCPL-WRCTL & + & + & $\mathbf{x}$ \\
\hline SH WDCPL-WDCTL & $x$ & $x$ & 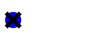 \\
\hline SH WRCPL-WRCTL & $x$ & $x$ & $\bullet$ \\
\hline
\end{tabular}

Figure 7. Indexes of latent $\left(I_{L H},+\right.$ crosses) and sensible $\left(I_{S H}, \mathrm{x}\right.$ crosses) heat flux differences calculated for every event (one cross is one event) in the zone named above each panel and plotted against the IPSS in the corresponding SST zone for WDCPL-WDCTL (blue crosses) and WRCPL-WRCTL (red crosses). Each cross is one event as selected in Table 3.

IPSS, and now that this IPSS for submonthly variations of SST is comparable between different datasets, we can use both WRCPL and ALCPL simulations together with CNR and OSTIA optimal interpolation products to give an estimation of the IPSS due to submonthly variations and an estimation of which HyMeX events may have been affected by these variations. For the three zones under consideration, Table 12 presents the events during HyMeX SOP 1 for which recorded daily precipitation exceeded $100 \mathrm{~mm}$ in the selection zones 
a. Cévennes

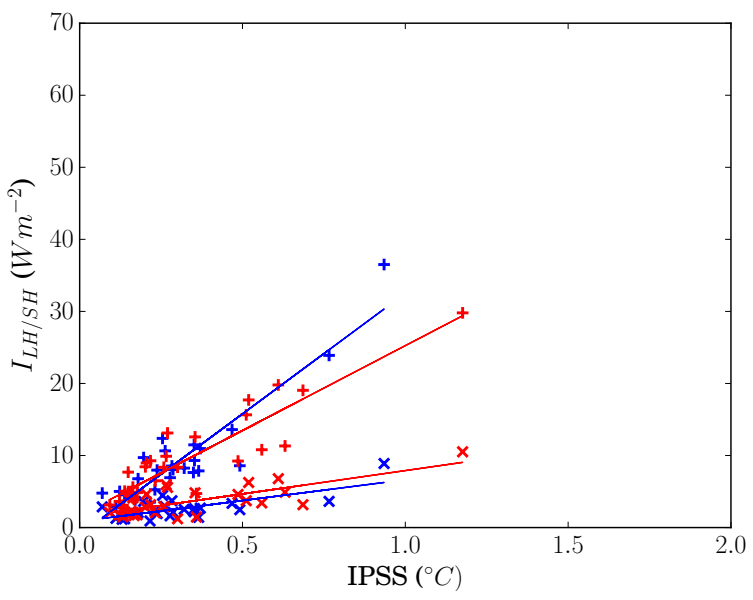

c. Calabria

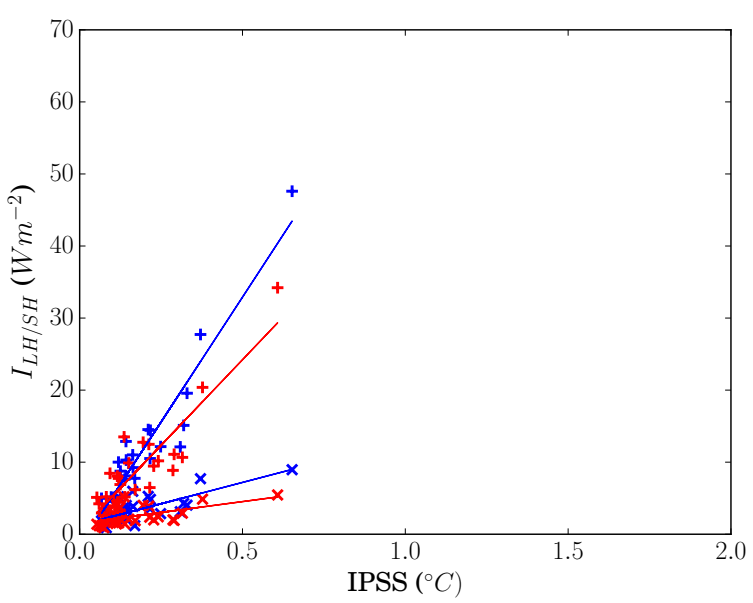

e. Northeastern Italy

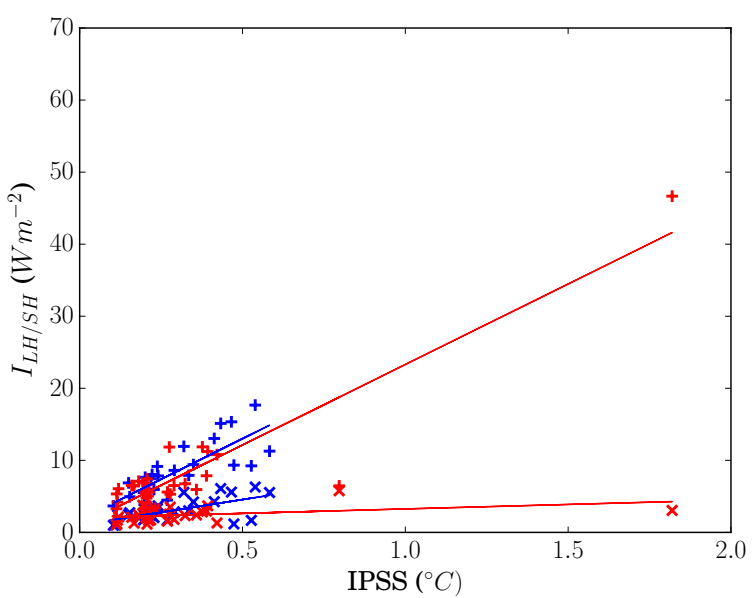

b. Valencia

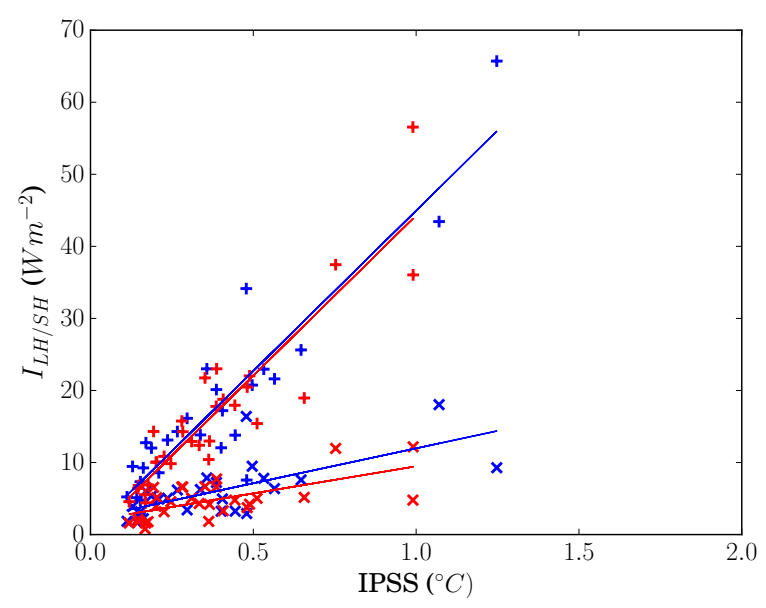

d. Central Italy

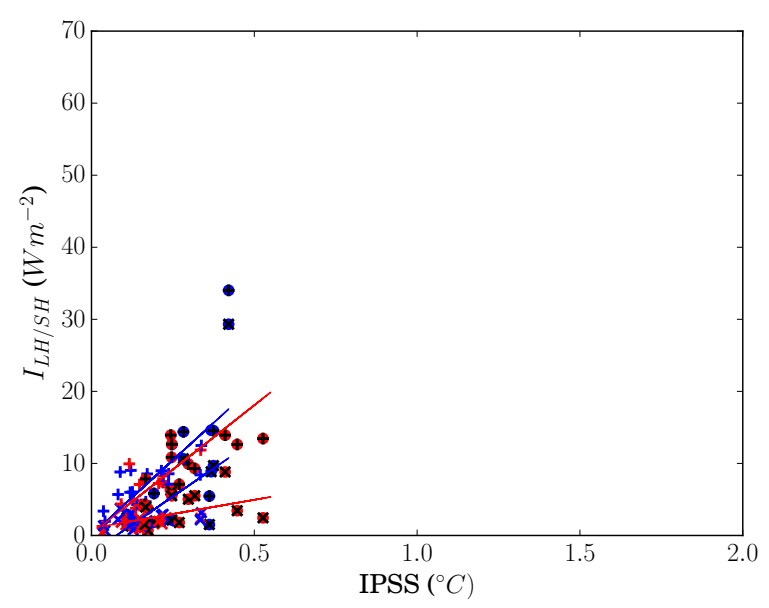

Figure 8. Same as Fig. 7 for WDCPL-WDSMO and WRCPL-WRSMO. Note the The scale is different.

defined in Fig. 2 (the rain gauge maximum is given for each date). The associated IPSS for each simulation or dataset is given. Using Fig. 6, an estimation of the relative $i_{\text {rain }}$, is given for the minimum, mean and maximum of the four IPSS. The $I_{\text {rain }} / P_{\max }$ WRCPLWRSMO, using the modeled $P_{\max }$ is also given when the original grid rain maximum in the model is larger than $30 \mathrm{~mm}$.

The results show that the events with large submonthly deviations of SST from the moving monthly average, which may modulate them, were 25 and 26 October in the Cévennes with statistical $i_{\text {rain }}$ of 
a. Cévennes

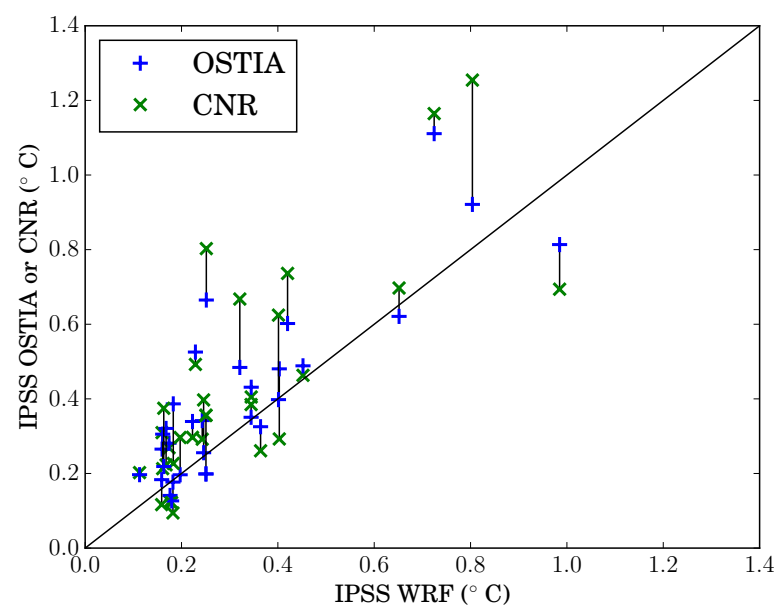

c. Calabria

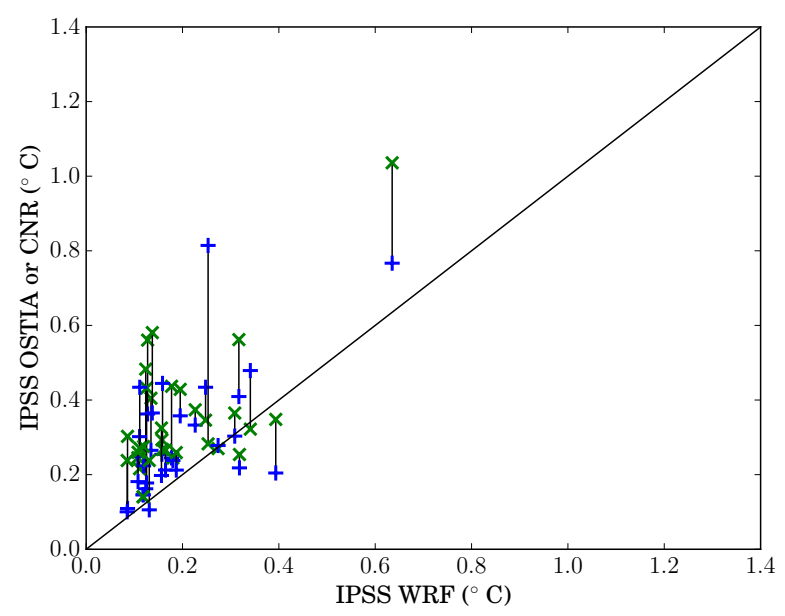

e. Northeastern Italy

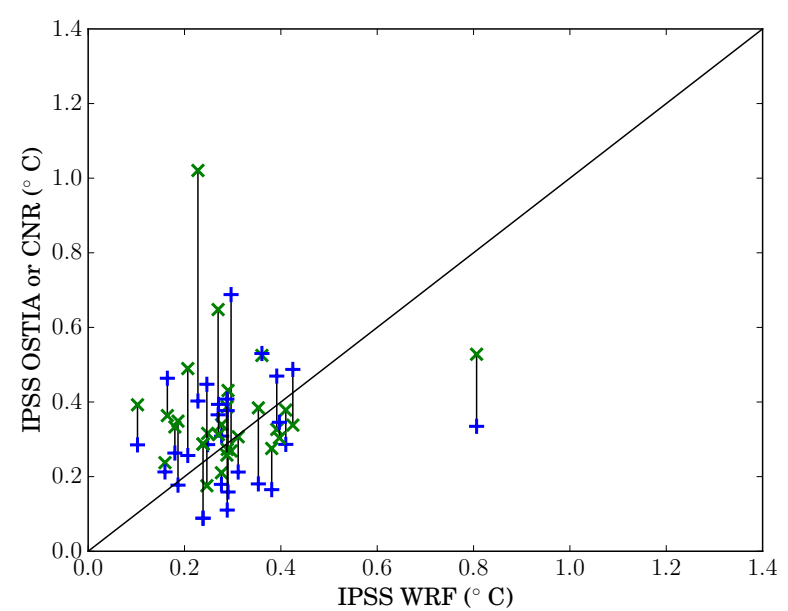

b. Valencia

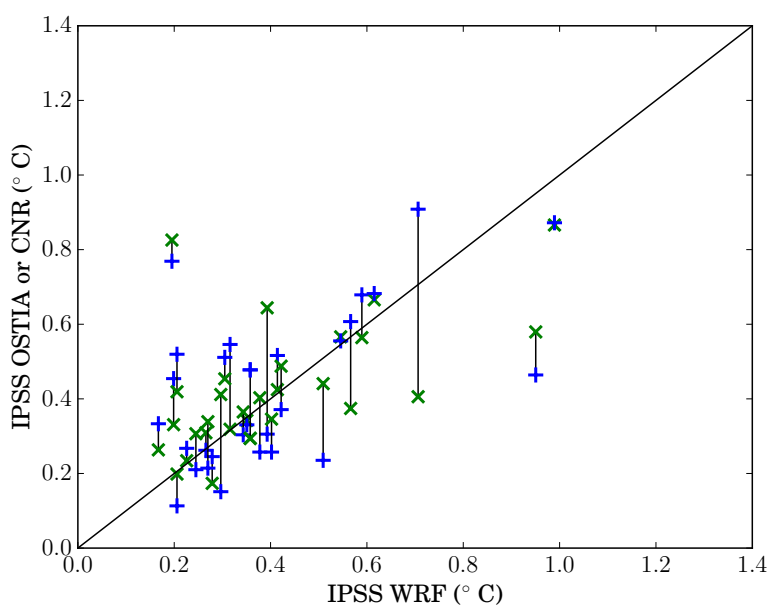

d. Central Italy

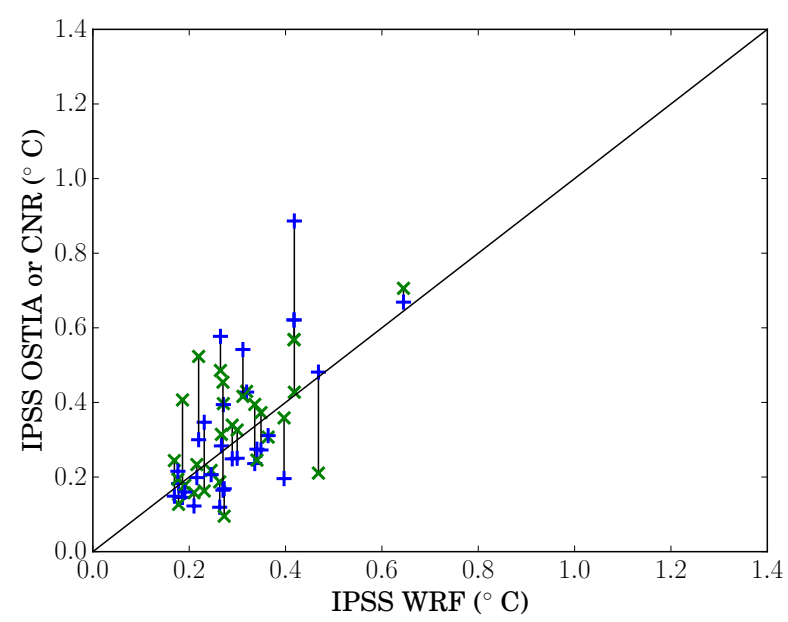

Figure 9. IPSS computed for WRCPL-WRSMO plotted against the IPSS calculated for the two datasets (blue + crosses: OSTIA dataset, green $\mathrm{x}$ crosses: CNR dataset, the black line in between links the same events). Each cross is one event as selected in Table 3. The black line is the unity line.

about 0.04 to 0.05 and 28 September and 12 October most events and gives a larger $i_{\text {rain }}$ for Calabria of for Valencia with estimated values of 0.05 and 0.07 . about 0.07 , which indicate that the event was more WRCPL-WRSMO is within the estimated range for sensitive to the SST changes than the average in 


\begin{tabular}{cccccc}
\hline & Cévennes & Valencia & Calabria & Central Italy & Northeastern Italy \\
\hline \hline & & & & & \\
OSTIA-WDCPL & $\mathbf{0 . 8 4}(\mathbf{0 . 9 3})$ & $\mathbf{0 . 5 0}(\mathbf{0 . 3 8})$ & $\mathbf{0 . 7 1}(\mathbf{0 . 8 3})$ & $\mathbf{0 . 6 6}(\mathbf{0 . 6 7})$ & $0.34(0.42)$ \\
CNR-WDCPL & $\mathbf{0 . 7 5}(\mathbf{0 . 9 0})$ & $\mathbf{0 . 5 8}(\mathbf{0 . 4 0})$ & $0.49(0.77)$ & $\mathbf{0 . 8 4}(\mathbf{0 . 7 8})$ & $0.26(0.36)$ \\
OSTIA-CNR & $\mathbf{0 . 9 0}(\mathbf{0 . 9 8})$ & $\mathbf{0 . 7 6}(\mathbf{0 . 6 8})$ & $\mathbf{0 . 6 2}(\mathbf{0 . 8 4})$ & $\mathbf{0 . 7 1}(\mathbf{0 . 6 5})$ & $0.10(0.12)$ \\
\hline \hline & & & & & \\
OSTIA-WRCPL & $\mathbf{0 . 8 4}(\mathbf{0 . 9 4})$ & $\mathbf{0 . 5 6}(\mathbf{0 . 5 7})$ & $\mathbf{0 . 5 9}(\mathbf{0 . 8 3})$ & $\mathbf{0 . 7 1}(\mathbf{1 . 1 3})$ & $\mathbf{0 . 8 7}(\mathbf{0 . 9 8})$ \\
CNR-WRCPL & $\mathbf{0 . 7 7}(\mathbf{1 . 0 5})$ & $\mathbf{0 . 5 8}(\mathbf{0 . 4 7})$ & $\mathbf{0 . 6 0}(\mathbf{0 . 8 5})$ & $\mathbf{0 . 8 6}(\mathbf{1 . 0 8 )}$ & $\mathbf{0 . 8 3}(\mathbf{0 . 8 6})$ \\
OSTIA-CNR & $\mathbf{0 . 9 1}(\mathbf{1 . 1 2})$ & $\mathbf{0 . 6 4}(\mathbf{0 . 5 0})$ & $\mathbf{0 . 5 0}(\mathbf{0 . 5 0})$ & $\mathbf{0 . 8 3}(\mathbf{0 . 7 9})$ & $\mathbf{0 . 8 4}(\mathbf{0 . 7 8})$ \\
\hline \hline & & & & & \\
OSTIA-ALCPL & $\mathbf{0 . 7 9}(\mathbf{0 . 6 5})$ & $\mathbf{0 . 5 5}(\mathbf{0 . 6 5})$ & $0.24(0.31)$ & $\mathbf{0 . 7 4}(\mathbf{0 . 5 3})$ & $0.35(0.51)$ \\
CNR-ALCPL & $\mathbf{0 . 7 8}(\mathbf{0 . 7 6})$ & $\mathbf{0 . 6 2}(\mathbf{0 . 7 0})$ & $\mathbf{0 . 6 1}(\mathbf{0 . 8 7})$ & $\mathbf{0 . 8 4}(\mathbf{0 . 5 9})$ & $\mathbf{0 . 5 3}(\mathbf{0 . 7 2})$ \\
OSTIA-CNR & $\mathbf{0 . 8 7}(\mathbf{1 . 0 3})$ & $\mathbf{0 . 6 5}(\mathbf{0 . 6 3})$ & $0.32(0.35)$ & $\mathbf{0 . 7 4}(\mathbf{0 . 7 3})$ & $\mathbf{0 . 5 0}(\mathbf{0 . 4 7})$
\end{tabular}

Table 11. Pearson correlation coefficients $\mathrm{R}$ (and slope) for the submonthly variability between (1) OSTIA product vs the model (WDCPL, WRCPL or ALCPL), (2) CNR product vs the model and (3) the two products based on observations. Statistically significant coefficients of correlation above $99 \%$ using a Student-t test are indicated with bold font.

\begin{tabular}{ccccccccc}
\hline Region & $\begin{array}{c}\text { date } \\
\left(P_{\max }\right) \\
(\mathrm{mm})\end{array}$ & IOP & $\begin{array}{c}\text { IPSS } \\
\text { WRCPL } \\
\left({ }^{\circ} \mathrm{C}\right)\end{array}$ & $\begin{array}{c}\text { IPSS } \\
\text { ALCPL } \\
\left({ }^{\circ} \mathrm{C}\right)\end{array}$ & $\begin{array}{c}\text { IPSS } \\
\text { OSTIA } \\
\left({ }^{\circ} \mathrm{C}\right)\end{array}$ & $\begin{array}{c}\text { IPSS } \\
\mathrm{CNR} \\
\left({ }^{\circ} \mathrm{C}\right)\end{array}$ & $\begin{array}{c}i_{\text {rain }} \\
\text { estimate } \\
\text { min-mean-max }\end{array}$ & $\begin{array}{c}i_{\text {rain }} \\
\left(P_{\max } 20 \mathrm{~km}, \mathrm{~mm}\right)\end{array}$ \\
\hline \hline \multirow{2}{*}{ Cévennes } & $18 / 10(103)$ & 14 & 0.27 & 0.46 & 0.45 & 0.44 & $0.01-0.025-0.03$ & - \\
& $25 / 10(107)$ & $16 \mathrm{a}$ & 0.67 & 0.63 & 0.86 & 0.80 & $0.035-0.04-0.045$ & $0.07(53)$ \\
& $26 / 10(152)$ & $16 \mathrm{a}$ & 0.75 & 0.75 & 1.07 & 0.68 & $0.04-0.05-0.06$ & $0.06(30)$ \\
\hline \multirow{2}{*}{ Valencia } & $28 / 09(141)$ & 8 & 0.19 & 0.40 & 0.31 & 0.55 & $0.025-0.05-0.085$ & $0.04(34)$ \\
& $12 / 10(105)$ & $12 \mathrm{a}$ & 0.38 & 0.44 & 0.52 & 0.67 & $0.05-0.07-0.10$ & $0.09(31)$ \\
\hline \multirow{2}{*}{ Calabria } & $31 / 10(184)$ & - & 0.24 & 0.19 & 0.18 & 0.22 & $0.02-0.025-0.035$ & $0.07(117)$
\end{tabular}

Table 12. IPSS of the submonthly SST variations for the Hymex SOP1 events (Ducrocq et al. 2014) with cumulated rain larger than $100 \mathrm{~mm}$ in raingauges for models and datasets; estimated relative $i_{\text {rain }}$ (minimum, mean, maximum) using the relationship in Fig. 5 and the minimum, mean and maximum IPSS from datasets and models; $i_{\text {rain }}$ for the only available set of CPL-SMO simulations: WRCPL-WRSMO when maximum daily precipitation in the model is larger than $30 \mathrm{~mm}$ (and precipitation maximum).

this model. As shown in Fig. 3, 25 and 26 October (IOP 16a) are just followed by a very strong Mistral event from 27 to 30 October (IOP 16b), as studied by Lebeaupin Brossier et al. (2014), which makes the situation of the HPE in a peak of submonthly variations. The event of the 18 October is preceded by a weaker but longer Mistral event, which makes the submonthly variations not as strong on the event day. The 28 September in Valencia is preceded and followed by SST cooling in the Balearic sea linked with southeasterly and northeasterly winds while the 12 October is followed by strong northerly winds (not shown).

\section{Discussion and conclusion}

This study uses regional climate modeling to address the question of where extreme precipitation events are sensitive to sea surface temperature changes in direct upstream regions either caused by model biases or by air-sea submonthly coupling. This submonthly air-sea coupling is mostly linked with local strong wind regimes, their effect on the ocean dynamics and the SST and the corresponding atmospheric response. Regions where intense precipitation events occurred during HyMeX SOP1 (autumn 2012) were selected for the study: Valencia in Spain, the Cévennes in Southern France, Liguria in Northwestern Italy, Central Italy, Calabria and Northeastern Italy. The 30 most extreme events in hindcast simulations of a period of 20 to 24 years were selected for two models: the MORCE platform in two configurations (WR and WD, $20 \mathrm{~km}$ resolution) and the CNRM-RSCM4 (ALADIN, $50 \mathrm{~km}$ resolution).

Liguria was the only region excluded from the study since less than $25 \%$ of the observed events were represented by the models while this score was between 40 and $50 \%$ in the other regions where good quality gridded rain datasets were available, i.e. Valencia, the Cévennes and Northeastern Italy. For these zones, between 70 and $90 \%$ of the modeled extreme events were in the 100 largest observed events, which means that the selected events are HPEs, even if not all of them are extreme in reality. Even though Central Italy and Calabria did not show good hit rates, both regions were kept for the study since the E-OBS dataset used for these regions showed limited skills to evaluate the models. Though regional climate modeling does not capture events triggered 
or enhanced by subgrid mechanisms (cold pools, finescale topography interactions...) but rather the largescale forced events (linked to surface fronts and low-level convergence zones, interactions with largescale orography, tropospheric divergence, ...), it allows statistical studies of sensitivity to the changes in SST on this later sort of heavy precipitation events.

With the use of synthetic indexes ( $I_{\text {rain }}$ and IPSS), this study statistically shows that changes in extreme precipitation events represented by RCMs are linearly related to SST changes in the upstream zone that covers most of the low-level jets upstream of HPEs in three regions: the Cévennes in Southern France, Valencia in Spain and Calabria in Italy. This result is robust in both models. Changes in the convergence of moisture in the systems are linked with changes in low-level dynamics rather than in low-level specific humidity in both models. Changes in surface heat flux are responsible for the temperature changes at the origin of wind changes. The Cévennes shows a weaker sensitivity to SST compared to Spain and Calabria. Central Italy showed no convincing relationship between upstream SST differences and rain differences. However, heat flux differences showed a similar relationship with IPSS as in the other regions. Northeastern Italy showed weak sensitivity to SST changes except for a few events, presumably due to the narrow configuration of the Adriatic Sea and the dependency on the trajectory of the low-level jet (along or across the Adriatic sea).

Moreover, in the Cévennes, Valencia and Calabria, precipitation can be modulated by submonthly variations of $\mathrm{SST}$ (with an $I_{\text {rain }} / P_{\max }$ larger than 0.05). This means variations due to strong wind regimes or oceanic circulation. Valencia shows the largest modulation by these variations while Calabria shows the same sensitivity but weaker SST submonthly variations. However, the IPSS in the models is underestimated by about $0.1^{\circ} \mathrm{C}$ in this region. The Cévennes region has a weaker sensitivity but IPSS as strong as in Valencia. On the contrary, no significant effect of submonthly coupling on HPEs has been found for Northeastern Italy and a more random relation is found for Central Italy. Both situations (strong continental wind regimes and HPEs) happen separately but oceanic response can link them (Lebeaupin Brossier et al. (2013); Berthou et al. (2014) for the Cévennes). The synoptic link between strong wind regimes cooling the SST and HPEs is not investigated in this study and it is assumed that both types of events can happen independently. However, future work will study such links in Valencia where $S S T_{C P L}-S S T_{S M O}$ are predominantly negative (in $73 \%$ of the cases) while it is more equilibrated for the Cévennes (50\%) and Calabria $(60 \%)$.

The submonthly variations of SST in the models were then compared with the submonthly variations in high-resolution optimally-interpolated SST product in order to further validate the results. The models represent well the variations in the upstream region of the Cévennes, Valencia and Central Italy, where both datasets used for validation also agree with each other. In Calabria and Northeastern Italy, the two datasets OSTIA and CNR do not agree well: some of the model versions show some agreement with $\mathrm{CNR}$, others with
OSTIA but there is no clear agreement. Therefore, further work needs to be undertaken on these regions for the improvement of datasets and models in terms of submonthly variations of SST (representation of winds and of the ocean circulation at submonthly timescales), especially upstream of Calabria regarding the importance of SST variations in the modulation of the HPEs in this region.

Finally, submonthly variations of SST that occurred during the HyMeX events were calculated for both models and both datasets in order to know whether or not some rain events may have been influenced by such variations coming from air-sea coupling. Datasets and models provided a range of IPSS and the use of the above-mentionned relationships between IPSS and $i_{\text {rain }}$ gave a range of relative $i_{\text {rain }}$. It indicates that the events of 25 and 26 October in the Cévennes the 28 September and 12 October in Valencia were most probably modulated by variations in SST that occurred within 15 days of the event.

A first limit of our study is the use of only two AORCMs, which while very different were both shown to calculate excessively strong surface fluxes (Di Luca et al. 2014; Sevault et al. 2014). Further tests could be done with remote areas. Another limit is the lack of representation of fine-scale processes triggering and enhancing heavy rain events that are better represented in numerical weather prediction models at the scale of a few kilometers. We considered only 30 events so that 70 to $90 \%$ of them are in the 100 heaviest events of the datasets: we analysed HPEs represented by RCMs and missed the ones enhanced or triggered by subgrid mechanisms. This was a trade-off between representing both the atmosphere-ocean coupling and the HPEs in long simulations with an AORCM while keeping reasonable computational costs. This work should therefore be considered as a first approach. To keep the advantage of regional climate modeling as the possibility to look for statistical relationships on sensitivity experiments, regional climate convection permitting models with $1-4 \mathrm{~km}$ grid spacing are an interesting perspective (Kendon et al. 2014; Prein et al. 2015b). Further work is needed in order to understand specifically in each region the mechanisms at play linking low-level temperature differences arising from SST differences to rain differences through low-level wind changes but this is beyond the scope of the present study. Further work is also needed in the Eastern Mediterranean basin where strong air-sea interactions also occur at submonthly time-scales (e.g. the Etesians in Greece) and heavy precipitation events are also at play.

\section{Acknowledgement}

This work is part of the Med-CORDEX initiative (www.medcordex.eu) supported by the HyMeX programme (www.hymex.org) through INSU-MISTRALS support. This research has received funding from the French National Research Agency (ANR) project REMEMBER (contract ANR-12-SENV-001). It was supported by the IPSL group for regional climate and environmental studies, with granted access to the HPC resources of IDRIS (under allocation i2011010227). The authors acknowledge the HyMeX database 
teams (ESPRI/IPSL and SEDOO/Observatoire MidiPyrénés) for their help in accessing the data. We thank the MYOCEAN project for providing the CNR-ISACGOS SST product and OSTIA product.

We acknowledge the E-OBS dataset from the EU-FP6 project ENSEMBLES (http://ensembleseu.metoffice.com) and the data providers in the ECA\&D project (http://www.ecad.eu). The authors are thankful to the reviewers for their useful criticism which lead to the improvement of the paper and to Robert Jones for correcting the language.

\section{References}

Balmaseda MA, Mogensen K, Molteni, F, Weaver AT. 2010. The nemovar-combine ocean re-analysis. Technical report.

Béranger K, Drillet Y, Houssais MN, Testor P, Bourdallé-Badie R, Alhammoud B, Bozec A, Mortier L, Bouruet-Aubertot P, Crépon M. 2010. Impact of the spatial distribution of the atmospheric forcing on water mass formation in the Mediterranean sea. J. Geophys. Res. Oceans. 115(C12), doi: 10.1029/2009JC005648.

Berthou S, Mailler S, Drobinski P, Arsouze T, Bastin S, Béranger K, Lebeaupin Brossier C. 2014. Prior history of mistral and tramontane winds modulates heavy precipitation events in southern France. Tellus A 66(0), doi:10.3402/tellusa.v66. 24064 .

Berthou S, Mailler S, Drobinski P, Arsouze T, Bastin S, Béranger K, Lebeaupin Brossier C. 2015. Sensitivity of an intense rain event between atmosphere-only and atmosphereocean regional coupled models: 19 september 1996. Q. J. R. Meteorol. Soc. 141: 258-271, doi:10.1002/qj.2355.

Beuvier J, Béranger K, Lebeaupin Brossier C, Somot S, Sevault F, Drillet Y, Bourdallé-Badie R, Ferry N, Lyard F. 2012. Spreading of the western Mediterranean deep water after winter 2005: Time scales and deep cyclone transport. $J$. Geophys. Res. 117: C07 022, doi:10.1029/2011JC007679.

Beuvier J, Sevault F, Herrmann M, Kontoyiannis H, Ludwig W, Rixen M, Stanev E, Béranger K, Somot S. 2010. Modeling the Mediterranean sea interannual variability during 1961-2000: Focus on the eastern Mediterranean transient. J. Geophys. Res. Oceans. 115: C08 017, doi:10.1029/2009JC005950.

Bougeault P. 1985. A simple parameterization of the largescale effects of cumulus convection. Mon. Weather Rev. 113(12): $8-2121$.

Brankart J, Brasseur P. 1998. The general circulation in the Mediterranean sea: a climatological approach. J. Marine Syst. 18(1-3): 41-70, doi:10.1016/S0924-7963(98)00005-0.

Bresson E, Ducrocq V, Nuissier O, Ricard D, de Saint-Aubin C. 2012. Idealized numerical simulations of quasi-stationary convective systems over the northwestern Mediterranean complex terrain. Q. J. R. Meteorol. Soc. 138(668): 1751-1763, doi:10.1002/qj.1911.

Buongiorno Nardelli B, Tronconi C, Pisano A. 2014. MyOcean PRODUCT USER MANUAL for reprocessed level 4 SST products over the mediterranean and black seas. MyOcean .

Chronis T, Papadopoulos V, Nikolopoulos EI. 2011. QuickSCAT observations of extreme wind events over the Mediterranean and Black Seas during 2000-2008. Int. J. Climatol. 31(14): 2068-2077, doi:10.1002/joc.2213.

Colin J. 2012. Étude des événements précipitants intenses en méditerranée: approche par la modélisation climatique régionale. $\mathrm{PhD}$ thesis, Université Paul Sabatier, Toulouse 3, Toulouse, France.

Colin J, Déqué M, Radu R, Somot S. 2010. Sensitivity study of heavy precipitation in limited area model climate simulations: influence of the size of the domain and the use of the spectral nudging technique. Tellus A 62(5): 591-604, doi:10.1111/j. 1600-0870.2010.00467.x.

Decharme B, Alkama R, Douville H, Becker M, Cazenave A. 2010. Global evaluation of the ISBA-TRIP continental hydrological system. part ii: Uncertainties in river routing simulation related to flow velocity and groundwater storage. Bull. Am. Meteorol. Soc. 11: 601-617, doi:10.1175/ 2010JHM1212.1.

Dee DP, Uppala SM, Simmons AJ, Berrisford P, Poli P, Kobayashi S, Andrae U, Balmaseda MA, Balsamo G, Bauer P, Bechtold P, Beljaars ACM, van de Berg L, Bidlot J, Bormann N, Delsol C, Dragani R, Fuentes M, Geer AJ, Haimberger L, Healy SB, Hersbach H, Hlm EV, Isaksen L, Kllberg P, Khler M, Matricardi M, McNally AP, Monge-Sanz BM, Morcrette JJ, Park BK, Peubey C, de Rosnay P, Tavolato C, Thépaut JN, Vitart F. 2011. The ERA-Interim reanalysis: configuration and performance of the data assimilation system. Q. J. R. Meteorol. Soc. 137(656): 553-597, doi:10.1002/qj.828.

Déqué M, Somot S. 2008. Extreme precipitation and high resolution with aladin. Idjaras Quaterly Journal of the Hungarian Meteorological Service 112: 179-190.

Di Luca A, Flaounas E, Drobinski P, Brossier CL. 2014. The atmospheric component of the mediterranean sea water budget in a wrf multi-physics ensemble and observations. Clim. Dyn. 43(9-10): 2349-2375.

Donlon C, Martin M, Stark J, Roberts-Jones J, Fiedler E, Wimmer W. 2011. The operational sea surface temperature and sea ice analysis (OSTIA) system. Remote Sensing of the Environment doi:10.1016/j.rse.2010.10.017.

Drobinski P, Anav A, Lebeaupin Brossier C, Samson G, Stéfanon M, Bastin S, Baklouti M, Béranger K, Beuvier J, BourdalléBadie R, Coquart L, D'Andrea F, de Noblet-Ducoudré N, Diaz F, Dutay JC, Ethe C, Foujols MA, Khvorostyanov D, Madec G, Mancip M, Masson S, Menut L, Palmieri J, Polcher J, Turquety S, Valcke S, Viovy N. 2012. Model of the regional coupled earth system (MORCE): application to process and climate studies in vulnerable regions. Environ. Modell. Softw. 35: 1-18, doi:10.1016/j.envsoft.2012.01.017.

Drobinski P, Bastin S, Guénard V, Caccia J, Dabas AM, Delville P, Protat A, Reitebuch O, Werner C. 2005. Summer mistral at the exit of the rhône valley. Q. J. R. Meteorol. Soc. 131: 353-375.

Drobinski P, Ducrocq V, Alpert P, Anagnostou E, Béranger K, Borga M, Braud I, Chanzy A, Davolio S, Delrieu G, Estournel C, Boubrahmi NF, Font J, Grubisic V, Gualdi S, Homar V, Ivancan-Picek B, Kottmeier C, Kotroni V, Lagouvardos K, Lionello P, Llasat M, Ludwig W, Lutoff C, Mariotti A, Richard E, Romero R, Rotunno R, Roussot O, Ruin I, Somot S, Taupier-Letage I, Tintore J, Uijlenhoet R, Wernli H. 2014. HyMeX, a 10-year multidisciplinary program on the Mediterranean water cycle. Bull. Am. Meteorol. Soc. 95: 1063-1082, doi:10.1175/BAMS-D-12-00242.1.

Drobinski P, Flamant C, Dusek J, Flamant P, Pelon J. 2001. Observational evidence and modeling of an internal hydraulic jump at the atmospheric boundary layer top during a tramontane event. Boundary-Layer Meteorol. 98: 497-515.

Ducrocq V, Braud I, Davolio S, Ferretti R, Flamant C, Jansà A, Kalthoff N, Richard E, Taupier-Letage I, Ayral PA, Belamari $\mathrm{S}$, Berne A, Borga M, Boudevillain B, Bock O, Boichard JL, Bouin MN, Bousquet O, Bouvier C, Chiggiato J, Cimini D, Corsmeier U, Coppola L, Cocquerez P, Defer E, Delanoë J, Di Girolamo P, Doerenbecher A, Drobinski P, Dufournet Y, Fourrié N, Gourley JJ, Labatut L, Lambert D, Le Coz J, Marzano FS, Molinié G, Montani A, Nord G, Nuret M, Ramage K, Rison B, Roussot O, Said F, Schwarzenboeck A, Testor P, Van-Baelen J, Vincendon B, Aran M, Tamayo J. 2014. HyMeX-SOP1, the field campaign dedicated to heavy precipitation and flash flooding in the northwestern Mediterranean. Bull. Am. Meteorol. Soc. 95(7): 1083-1100, doi:10.1175/BAMS-D-12-00244.1.

Ducrocq V, Nuissier O, Ricard D, Lebeaupin C, Thouvenin T. 2008. A numerical study of three catastrophic precipitating events over southern France. II: mesoscale triggering and stationarity factors. Q. J. R. Meteorol. Soc. 134(630): 131145, doi:10.1002/qj.199.

Duffourg F, Ducrocq V. 2011. Origin of the moisture feeding the heavy precipitating systems over southeastern France. Nat. Hazards Earth Syst. Sci. 11(4): 1163-1178, doi:10.5194/ nhess-11-1163-2011. 
Flamant C. 2003. Alpine lee cyclogenesis influence on airsea heat exchanges and marine atmospheric boundary layer thermodynamics over the western Mediterranean during a Tramontane/Mistral event. J. Geophys. Res. 108(C2), doi: 10.1029/2001JC001040.

Flaounas E, Drobinski P, Borga M, Calvet JC, Delrieu G, Morin E, Tartari G, Toffolon R. 2012. Assessment of gridded observations used for climate model validation in the Mediterranean region: the HyMeX and MED-CORDEX framework. Environ. Res. Lett. 7(2): 024017, doi:10.1088/ 1748-9326/7/2/024017.

Flaounas E, Drobinski P, Vrac M, Bastin S, Lebeaupin-Brossier C, Stéfanon M, Borga M, Calvet JC. 2013. Precipitation and temperature spacetime variability and extremes in the Mediterranean region: evaluation of dynamical and statistical downscaling methods. Clim. Dyn. 40(11-12): 2687-2705, doi: $10.1007 / \mathrm{s} 00382-012-1558-\mathrm{y}$.

Frei C, Schll R, Fukutome S, Schmidli J, Vidale PL. 2006. Future change of precipitation extremes in Europe: Intercomparison of scenarios from regional climate models. J. Geophys. Res. 111(D6), doi:10.1029/2005JD005965.

García-Herrera R, Barriopedro D, Hernández E, Paredes D, Correoso JF, Prieto L. 2005. The 2001 mesoscale convective systems over iberia and the balearic islands. Meteorol. Atmos. Phys. 90(3-4): 225-243, doi:10.1007/s00703-005-0114-2.

Garreau P, Garnier V, Schaeffer A. 2011. Eddy resolving modelling of the Gulf of Lions and Catalan Sea. Ocean Dynamics 61(7): 991-1003, doi:10.1007/s10236-011-0399-2.

Geleyn JF. 1988. Interpolation of wind, temperature and humidity values from model levels to the height of measurement. Tellus A 40: 347-351.

Giorgi F, Jones C, Asrar GR. 2009. Addressing climate information needs at the regional level: the CORDEX framework. WMO Bulletin 58(3): 175.

Grisogono B, Belušić D. 2009. A review of recent advances in understanding the meso- and microscale properties of the severe Bora wind. Tellus A 61(1): 1-16, doi:10.1111/j. 1600-0870.2008.00369.x.

Guénard V, Drobinski P, Caccia J, Campistron B, Bénech B. 2005. An observational study of the mesoscale mistral dynamics. Boundary-Layer Meteorol. 115: 263-288.

Guénard V, Drobinski P, Caccia J, G T, P C. 2006. Dynamics of the MAP IOP-15 severe mistral event: Observations and highresolution numerical simulations. Q. J. R. Meteorol. Soc. 132: 757-778.

Haugen JE, Machenhauer B. 1993. A spectral limited-area model formulation with time dependent boundary conditions applied to the shallow-water equations. Mon. Weather Rev. 121: 2618-2630.

Haylock M, Hofstra N, Klein Tank A, Klok E, Jones P, M N. 2008. A European daily high-resolution gridded dataset of surface temperature and precipitation. J. Geophys. Res. Atmos. 113: D20 119, doi:10.1029/2008JD10201.

Herrera S, Fita L, Fernández J, Gutiérrez JM. 2010. Evaluation of the mean and extreme precipitation regimes from the ENSEMBLES regional climate multimodel simulations over Spain. J. Geophys. Res. 115(D21), doi:10.1029/ 2010JD013936.

Herrera S, Gutierrez J, Ancell R, MR P, Frias M, Fernandez J. 2012. Development and analysis of a 50 year high-resolution daily gridded precipitation dataset over Spain (spain02). Int. J. Climatol. 32: 74-85, doi:10.1002/joc.2256.

Herrmann M, Somot S, Calmanti S, Dubois C, F S. 2011. Representation of daily wind speed spatial and temporal variability and intense wind events over the mediterranean sea using dynamical downscaling : impact of the regional climate model configuration. Nat. Hazards Earth Syst. Sci. 11: 19832001, doi:10.5194/nhess-11-1983-2011.

Hoinka KP, Schwierz C, Martius O. 2006. Synoptic-scale weather patterns during Alpine heavy rain events. Q. J. R. Meteorol. Soc. 132(621): 2853-2860, doi:10.1256/qj.05.239.

Houpert L, Testor P, Durrieu de Madron X, Somot S, DOrtenzio F, Estournel C, Lavigne H. 2015. Seasonal cycle of the mixed layer, the seasonal thermocline and the upper-ocean heat storage rate in the Mediterranean Sea derived from observations. Progress in Oceanography 132: 333-352, doi: 10.1016/j.pocean.2014.11.004

Houze RA. 2004. Mesoscale convective systems. Rev. Geophys. 42(4), doi:10.1029/2004RG000150.

Isotta F, Frei C, Weilguni V, Perčec Tadić M, Lasssègues P, Rudolf B, Pavan V, Cacciamani C, Antolini G, Ratto SM, Munari M, Micheletti S, Bonati V, Lussana C, Ronchi C, Panettieri E, Marigo G, Vertačni G. 2014. The climate of daily precipitation in the Alps: development and analysis of a highresolution grid dataset from pan-Alpine rain-gauge data. Int. J. Climatol. 34: 1657-1675, doi:10.1002/joc.3794.

Jansà A, Genovés A, Picornell M, Campins J, Riosalido R, Carretero O. 2001. Western Mediterranean cyclones and heavy rain. part 2: Statistical approach. Meteorol. Appl. 8(1): 43-56.

Kain JS. 2004. The Kain-Fritsch convective parameterization: An update. J. Appl. Meteorol. 43(1): 170-181, doi:10.1175/ 1520-0450(2004)043.

Katsafados P, Mavromatidis E, Papadopoulos A, Pytharoulis I. 2011. Numerical simulation of a deep Mediterranean storm and its sensitivity on sea surface temperature. Nat. Hazards Earth Syst. Sci. 11(5): 1233-1246, doi:10.5194/ nhess-11-1233-2011.

Kendon EJ, Roberts NM, Fowler HJ, Roberts MJ, Chan SC, Senior CA. 2014. Heavier summer downpours with climate change revealed by weather forecast resolution model. Nature Climate Change 4: 570576, doi:doi:10.1038/nclimate2258.

Kyselý J, Beguería S, Beranová R, Gaál L, López-Moreno JI. 2012. Different patterns of climate change scenarios for short-term and multi-day precipitation extremes in the Mediterranean. Global Planet. Change 98-99: 63-72, doi: 10.1016/j.gloplacha.2012.06.010.

Lebeaupin C, Ducrocq V, Giordani H. 2006. Sensitivity of torrential rain events to the sea surface temperature based on high-resolution numerical forecasts. J. Geophys. Res. Atmos. 111(D12), doi:10.1029/2005JD006541.

Lebeaupin Brossier C, Arsouze T, Branger K, Bouin MN, Bresson E, Ducrocq V, Giordani H, Nuret M, Rainaud R, Taupier-Letage I. 2014. Ocean Mixed Layer responses to intense meteorological events during HyMeX-SOP1 from a high-resolution ocean simulation. Ocean Modell. 84: 84-103, doi:10.1016/j.ocemod.2014.09.009.

Lebeaupin Brossier C, Bastin S, Béranger K, Drobinski P. 2015. Regional mesoscale airsea coupling impacts and extreme meteorological events role on the Mediterranean Sea water budget. Clim. Dyn. 44: 1029-1051, doi:10.1007/ s00382-014-2252-z.

Lebeaupin Brossier C, Béranger K, Deltel C, Drobinski P. 2011. The Mediterranean response to different spacetime resolution atmospheric forcings using perpetual mode sensitivity simulations. Ocean Modell. 36(1-2): 1-25, doi: 10.1016/j.ocemod.2010.10.008.

Lebeaupin Brossier C, Drobinski P. 2009. Numerical highresolution air-sea coupling over the gulf of lions during two tramontane/mistral events. J. Geophys. Res. 114(D10), doi: 10.1029/2008JD011601.

Lebeaupin Brossier C, Drobinski P, Béranger K, Bastin S, Orain F. 2013. Ocean memory effect on the dynamics of coastal heavy precipitation preceded by a mistral event in the northwestern Mediterranean. Q. J. R. Meteorol. Soc. 139: 1583-1897, doi:10.1002/qj.2049.

Levitus S, Antonov J, Boyer T. 2005. Warming of the world ocean, 1955-2003. Geophys. Res. Lett. 32(2), doi:10.1029/ 2004GL021592.

Louis JF. 1979. A parametric model of vertical eddy fluxes in the atmosphere. Boundary-Layer Meteorol. 17: 197-202.

Madec G, the NEMO Team. 2008. Nemo ocean engine. Technical report, Institut Pierre-Simon Laplace (IPSL), France.

Martínez C, Campins J, Jansà A, Genovés A. 2008. Heavy rain events in the western Mediterranean: an atmospheric pattern classification. Advances in Science and Research 2: 61-64, doi: 10.5194/asr-2-61-2008. 
Martius O, Schwierz C, Davies HC. 2008. Far-upstream precursors of heavy precipitation events on the Alpine southside. Q. J. R. Meteorol. Soc. 134(631): 417-428, doi:10.1002/ qj.229.

Millán M, Estrela MJ, Caselles V. 1995. Torrential precipitations on the Spanish east coast: the role of the Mediterranean sea surface temperature. Atmos. Res. 36(1): 1-16, doi:10.1016/ 0169-8095(94)00048-I.

Millot C. 1999. Circulation in the western mediterranean sea. Journal of Marine Systems 20(1): 423-442.

Morcrette JJ. 1989. Description of the radiation scheme in the ecmwf model. Technical report, ECMWF.

Nabat P, Somot S, Mallet M, Sevault F, Chiacchio M, Wild M. 2015. Direct and semi-direct aerosol radiative effect on the Mediterranean climate variability using a coupled regional climate system model. Clim. Dyn. 44: 1127-1155, doi:10. 1007/s00382-014-2205-6.

Noh Y, Cheon WG, Hong SY, Raasch S. 2003. Improvement of the k-profile model for the planetary boundary layer based on large eddy simulation data. Boundary-Layer Meteorol. 107(2): 401-427, doi:10.1023/A:1022146015946.

Noilhan J, Mahfouf JF. 1996. The ISBA land surface parameterisation scheme. Global Planet. Change 13: 145-159, doi:10.1016/0921-8181(95)00043-7.

Nuissier O, Ducrocq V, Ricard D, Lebeaupin C, Anquetin S. 2008. A numerical study of three catastrophic precipitating events over southern France. i: Numerical framework and synoptic ingredients. Q. J. R. Meteorol. Soc. 134(630): 111130, doi:10.1002/qj.200.

Nuissier O, Joly B, Joly A, Ducrocq V, Arbogast P. 2011. A statistical downscaling to identify the large-scale circulation patterns associated with heavy precipitation events over southern France. Q. J. R. Meteorol. Soc. 137(660): 18121827, doi:10.1002/qj.866.

Omrani H, Drobinski P, Dubos T. 2013. Optimal nudging strategies in regional climate modelling: investigation in a big-brother experiment over the European and Mediterranean regions. Clim. Dyn. 41: 2451-2470, doi:10. 1007/s00382-012-1615-6.

Pastor F, Estrela MJ, Peñarrocha D, Millán MM. 2001. Torrential rains on the Spanish Mediterranean coast: Modeling the effects of the sea surface temperature. J. Appl. Meteorol. 40(7): 1180-1195, doi:10.1175/1520-0450(2001) 040<1180:TROTSM $>2.0 . \mathrm{CO} ; 2$.

Pastor F, Gmez I, Estrela MJ. 2010. Numerical study of the October 2007 flash flood in the Valencia region (Eastern Spain): the role of orography. Nat. Hazards Earth Syst. Sci. 10(6): 1331-1345, doi:10.5194/nhess-10-1331-2010.

Pastor F, Valiente JA, Estrela MJ. 2015. Sea surface temperature and torrential rains in the Valencia region: modelling the role of recharge areas. Nat. Hazards Earth Syst. Sci. 3(2): 13571396, doi:10.5194/nhessd-3-1357-2015.

Prein AF, Gobiet A, Truhetz H, Keuler K, Goergen K, Teichmann C, Fox Maule C, van Meijgaard E, Déqué M, Nikulin G, Vautard R, Colette A, Kjellstrm E, Jacob D. 2015a. Precipitation in the EURO-CORDEX $0.11^{\circ}$ and $0.44^{\circ}$ simulations: high resolution, high benefits? Clim. Dyn. doi: 10.1007/s00382-015-2589-y.

Prein AF, Holland GJ, Rasmussen RM, Done J, Ikeda K, Clark MP, Liu CH. 2013. Importance of Regional Climate Model Grid Spacing for the Simulation of Heavy Precipitation in the Colorado Headwaters. J. Climate 26(13): 4848-4857, doi: 10.1175/JCLI-D-12-00727.1.

Prein AF, Langhans W, Fosser G, Ferrone A, Ban N, Goergen K, Keller M, Tlle M, Gutjahr O, Feser F, Brisson E, Kollet S, Schmidli J, van Lipzig NPM, Leung R. 2015b. A review on regional convection-permitting climate modeling: demonstrations, prospects, and challenges: Convection-permitting climate modeling. Rev. Geophys. doi: 10.1002/2014RG000475.

Quintana-Seguí P, Le Moigne P, Durand Y, Martin E, Habets F, Baillon M, Canellas C, Franchisteguy L, Morel S. 2008. Analysis of near-surface atmospheric variables: Validation of the SAFRAN analysis over France. J. Appl. Meteorol. 47(1):
92-107, doi:10.1175/2007JAMC1636.1.

Rajczak J, Pall P, Schär C. 2013. Projections of extreme precipitation events in regional climate simulations for Europe and the Alpine region. J. Geophys. Res. Atmos.

Ricard D, Ducrocq V, Auger L. 2012. A climatology of the mesoscale environment associated with heavily precipitating events over a northwestern Mediterranean area. J. Appl. Meteorol. 51(3): 468-488, doi:10.1175/JAMC-D-11-017.1.

Ricard JL, Royer JF. 1993. A statistical cloud scheme for use in an agcm. Ann. Geophys. Atmos. Hydrosph. Space Sc 11: 95-1115.

Riesco Martn J, Mora Garca M, de Pablo Dvila F, Soriano LR. 2014. Regimes of intense precipitation in the Spanish Mediterranean area. Atmos. Res. 137: 66-79, doi:10.1016/j. atmosres.2013.09.010.

Roberts-Jones J, Fiedler EK, Martin MJ. 2012. Daily, global, high-resolution SST and sea ice reanalysis for 1985-2007 using the OSTIA system. J. Climate (25): 6215-6232, doi: 10.1175/JCLI-D-11-00648.1.

Romero R, Sumner G, Ramis C, Genovés A. 1999. A classification of the atmospheric circulation patterns producing significant daily rainfall in the Spanish Mediterranean area. Int. J. Climatol. 19(7): 765-785, doi:10.1002/(SICI) 1097-0088(19990615)19:7〈765::AID-JOC388〉3.0.CO;2-T.

Rudari R, Entekhabi D, Roth G. 2005. Large-scale atmospheric patterns associated with mesoscale features leading to extreme precipitation events in northwestern Italy. Advances in Water Resources 28(6): 601-614, doi:10.1016/j.advwatres.2004.10. 017 .

Ruti P, Somot S, Giorgi F, Dubois C, Flaounas E, Obermann A, Dell'Aquila A, Pisacane G, Harzallah A, Lombardi E, Ahrens B, Akhtar N, Alias A, Arsouze T, Raznar R, Bastin S, Bartholy J, Béranger K, Beuvier J, Bouffies-Cloche S, Brauch J, Cabos W, Calmanti S, Calvet J, Carillo A, Conte D, Coppola E, Djurdjevic V, Drobinski P, Elizalde A, Gaertner M, Galan P, Gallardo C, Gualdi S, Goncalves M, Jorba O, Jorda G, Lheveder B, Lebeaupin-Brossier C, Li L, Liguori G, Lionello P, Macias-Moy D, Onol B, Rajkovic B, Ramage K, Sevault F, Sannino G, Struglia M, Sanna A, Torma C, Vervatis V. 2015. Med-cordex initiative for mediterranean climate studies. Bull. Am. Meteorol. Soc. .

Salameh T, Drobinski P, Dubos T. 2010. The effect of indiscriminate nudging time on large and small scales in regional climate modelling: Application to the Mediterranean basin. Q. J. R. Meteorol. Soc. 136(646): 170-182, doi:10. $1002 /$ qj. 518 .

Sánchez E, Gallardo C, Gaertner M, Arribas A, Castro M. 2004. Future climate extreme events in the Mediterranean simulated by a regional climate model: a first approach. Global Planet. Change 44(1-4): 163-180, doi:10.1016/j.gloplacha. 2004.06.010.

Sevault F, Somot S, Alias A, Dubois C, Lebeaupin-Brossier C, Nabat P, Adloff F, Déqué M, Decharme B. 2014. A fully coupled Mediterranean regional climate system model: design and evaluation of the ocean component for the 1980-2012 period. Tellus A 66, doi:10.3402/tellusa.v66.23967.

Simmons A, Uppala S, Dee D, Kobayashi S. 2007. New ECMWF reanalysis products from 1989 onwards. pp. 25-35.

Skamarock WC, Klemp JB, Dudhia J, Gill DO, Barker DM, Duda M, Huang XY, Wang W, Powers JG. 2008. A description of the advanced research WRF version 3. Technical report, DTIC Document.

Small R, Carniel S, Campbell T, Teixeira J, Allard R. 2012. The response of the Ligurian and Tyrrhenian Seas to a summer Mistral event: A coupled atmosphereocean approach. Ocean Modell. 48: 30-44, doi:10.1016/j.ocemod.2012.02.003.

Smith RNB. 1990. A scheme for predicting layer clouds and their water content in a general circulation model. $Q$. J. $R$. Meteorol. Soc. 116: 435-460, doi:10.1002/qj.49711649210.

Stauffer DR, Seaman NL. 1990. Use of four-dimensional data assimilation in a limited-area mesoscale model. part i: Experiments with synoptic-scale data. Mon. Weather Rev. 118(6): 1250-1277, doi:10.1175/1520-0493(1990)118. 
Stéfanon M, Drobinski P, DAndrea F, Lebeaupin-Brossier C, Bastin S. 2014. Soil moisture-temperature feedbacks at mesoscale during summer heat waves over Western Europe. Clim. Dyn. 42(5-6): 1309-1324.

Stull RB. 1994. An introduction to boundary layer meteorology. Kluwer: London, Royaume-Uni, ISBN 90-277-2769-4.

The PROTHEUS Group, Artale V, Calmanti S, Carillo A, Dell'Aquila A, Herrmann M, Pisacane G, Ruti PM, Sannino G, Struglia MV, Giorgi F, Bi X, Pal JS, Rauscher S. 2009. An atmosphere-ocean regional climate model for the Mediterranean area: assessment of a present climate simulation. Clim. Dyn. 35(5): 721-740, doi:10.1007/ s00382-009-0691-8.

Toreti A, Xoplaki E, Maraun D, Kuglitsch FG, Wanner H, Luterbacher J. 2010. Characterisation of extreme winter precipitation in Mediterranean coastal sites and associated anomalous atmospheric circulation patterns. Nat. Hazards Earth Syst. Sci. 10(5): 1037-1050, doi:10.5194/ nhess-10-1037-2010.

Valcke S. 2013. The OASIS3 coupler: a European climate modelling community software. Geosci. Model Dev. 6: 373388, doi:10.5194/gmdd-5-2139-2012. 